\title{
Influence of Graphene Nanosheets on Thermo-Physical and Tribological Properties of Sustainable Cutting Fluids for MQL Application in Machining Processes
}

\author{
Vitor Baldin \\ Pontifícia Universidade Católica do Paraná - PUC-PR \\ Leonardo R Ribeiro da Silva ( $\sim$ leonardo.rrs@gmail.com ) \\ Rogério Valentim Gelamo \\ Institute of Technogical and Exact Sciences \\ Adres Bustillo Iglesias \\ Universidad de Burgos \\ Rosemar Batista da Silva \\ Federal University of Uberlandia \\ Navneet Khanna \\ Institute of Infrastructure Technology \\ Alisson Rocha Machado \\ Pontifícia Universidade Católica do Paraná - PUC-PR
}

Universidade Federal de Uberlandia https://orcid.org/0000-0003-2777-4500

\section{Research Article}

Keywords: Graphene nanoparticles, Reciprocate sliding, Lubricity of cutting fluids, Ramp milling test, Vegetablebased cutting fluid.

Posted Date: August 27th, 2021

DOI: https://doi.org/10.21203/rs.3.rs-838748/v1

License: (9) (i) This work is licensed under a Creative Commons Attribution 4.0 International License. Read Full License 


\section{Abstract}

This study investigates the effects of applying two vegetable and one mineral-based cutting fluids with $0.05 \%$ wt and $0.1 \%$ wt dispersion of graphene sheets on the tribosystem generated at the interface between the cemented carbide tool and the AISI 1045 steel workpiece. The fluids are firstly characterized (viscosity, thermal conductivity and diffusivity, and wettability) and tested in reciprocating and ramp milling tests. The results show that the graphene sheets alter the thermo-physical and tribological properties of the cutting fluids; in this case, vegetable-based cutting fluids, even in minimum quantities and with graphene nanoparticles, have a high potential for increasing the efficiency and sustainability of the milling process.

\section{Introduction}

Understanding the machining interface's tribological behavior is crucial for modeling material removal processes using a defined geometry tool. To date, no model adequately describes the friction in the cutting areas [1]. Therefore, advances in understanding the contact conditions, the plastic deformation behavior, and the cutting temperatures involved contribute to describing the tribological behavior in this type of chaotic tribosystem [2, 3]. Among the various factors that affect the friction coefficient at the cutting interface, the type of work and tool materials, tool geometry, tool wear, and lubricating conditions can be highlighted. These factors are responsible for changes in the machining forces and heat generated in the cutting zones, and as such, they continuously change the tribosystem's behavior [4].

Tribological tests can help simulate the machining tribosystem, thus helping in understanding the friction coefficient behavior and tool wear $[5,6]$. However, conventional tribometers can reproduce the friction coefficient at the cutting interface but with reservations because of the low relative velocities, contact pressures, and temperatures at the interface between the workpiece and the counterbody compared to the machining conditions [7, 8], resulting in poor quantitative predictions [3]. One alternative for better simulation is to adapt machine centers as open tribometers [3, 9]. This type of tribometers is often presented as an alternative to a more detailed investigation of the tribological aspects of machining [10], thus allowing for the use of test parameters that are closer to those used in actual machining conditions $[2,11,12]$.

To reduce friction and heat generation during machining, cutting fluid is typically used. The lubricating efficiency depends on the fluids' ability to penetrate and form a lubricant film at the workpiece-tool-chip contact regions to reduce friction and decrease material adhesion on the tool $[13,14]$. Tribofilm formation reduces friction between contact surfaces, reducing heat generation and wear [15]. The literature is scarce regarding the tribological effects of graphene sheets in the cutting fluid on the machining process [16]. However, because of the atoms' covalent bonds, graphene presents excellent mechanical properties [17] and can act as an extreme pressure self-lubricating system that justifies its tribological applications [18]. Furthermore, graphene increases the cutting fluids' wettability [19] and reduces the machining temperature regardless of the fluid flow applied [20]. Past studies indicate that the use of graphene combined with other particles such as aluminum oxide $\left(\mathrm{Al}_{2} \mathrm{O}_{3}\right)$ [21] and silver $(\mathrm{Ag})$ [22] can further enhance their tribological behavior in the machining process.

This paper aims at investigating the influence of the addition of graphene sheets (two concentrations: $0.05 \% \mathrm{wt}$ and $0.1 \% \mathrm{wt}$ ) in three different cutting fluids (two vegetable and one mineral-based) on their thermo-physical and tribological properties during reciprocating and face milling tests, the latter used as an open tribometer $[3,9]$.

\section{Experimental Methods And Materials}




\subsection{Workpiece Materials}

In this study, AISI 1045 steel was used as the workpiece material, having the conventional microstructure composed predominantly of coarse perlite grains and ferrite, according to Fig. 1. The material was characterized regarding its stress-strain behavior according to the ASTM [23] standard, resulting in an average of ultimate tensile strength of $869 \mathrm{MPa}$ and $13.60 \%$ strain, and regarding its hardness according to ASTM [24] standard, resulting in an average hardness of $262 \pm 11.35 \mathrm{HV} 1$.

\subsection{Cutting fluids}

Three different cutting fluids were evaluated, two of which are manufactured by SpecialMix Industrial Ltda (MQL14 and MQL15) and manufactured by ITW Chemical Products Ltda (LB 1000). Both MQL15 and LB 1000 are vegetablebased, and the MQL 14 is mineral-based, with the main characteristics of the fluids summarized in Table 1. The three oils were tested pure and with graphene additions in two concentrations, $0.05 \%$ wt and $0.1 \%$ wt. For the homogenization of graphene sheets in the oil samples, initially, they were manually stirred up for 5 minutes and then sonicated for 10 minutes.

Table 1

- Cutting fluids characteristics.

\begin{tabular}{|llll|}
\hline Characteristics & MQL14 & MQL15 & LB1000 \\
\hline Visual aspect & Clear, opaque viscous liquid & Clear liquid & Opaque viscous liquid \\
\hline Color & Light green & Red & Light blue \\
\hline Viscosity (CSt) at $40^{\circ} \mathrm{C}$ & $9.5 / 10.5$ & 60 to 70 & 39 \\
\hline Flash point (ASTM D92) $\left({ }^{\circ} \mathrm{C}\right)$ & $>250$ & $<180$ & $>204$ \\
\hline Freezing point $\left({ }^{\circ} \mathrm{C}\right)$ & -10 & -10 & -15 \\
\hline Boiling point $\left({ }^{\circ} \mathrm{C}\right)$ & $>270$ & $>270$ & $>279$ \\
\hline density $\left(\mathbf{2 0} / 4^{\circ} \mathrm{C}\right)(\mathrm{kg} / \mathrm{l})$ & 0,902 & 0,920 & 0,930 \\
\hline Solubility in water & Insoluble & Insoluble & Insoluble \\
\hline
\end{tabular}

An image of the graphene sheets taken within the scanning electron microscope (SEM) model TESCAN VEGA3 LMU is shown in Fig. 2. Graphene's morphology resembles a folded sheet composed of multilayers and irregular edges due to the mechanical exfoliation process [25]. These edge defects originate from breaking carbon in the planes, causing structural disorder at these points [26]. A sequence of 10 measurements of the dimensions of the sheets was made, indicating an average thickness of $36.83 \pm 3.22 \mathrm{~nm}$.

Graphene sheets were also analyzed using a transmission electron microscope (TEM) JEOL JEM 1200EX-II (TEM). Figure 3a presents an image of a graphene particle with multiple layers (or sheets) identified by electron diffraction (Fig. 3b), where the external hexagonal (arrangement of the carbon atoms) has an intensity equal to or greater than the internal hexagonal. These results are consistent with the studies [27-30] and prove that the graphene particles added to the fluids are composed of mono and multilayers.

The dynamic and kinematic viscosities and the specific mass are important parameters used to evaluate and monitor the cutting oils. These parameters were measured on an Anton Paar viscometer, model SVMTM 3000. The 
viscometer is accurate to the range described in ASTM D445-18 [31], and the measurement method was according to ASTM D2270-10 [32].

The tests for measuring specific heat, diffusivity, and thermal conductivity were performed on the Transient Hot Bridge equipment, model Linseis, with a measurement range for specific heat from 100 to $5000 \mathrm{~kJ} /\left(\mathrm{m}^{3} \mathrm{~K}\right)$, diffusivity from 0.05 to $10 \mathrm{~mm}^{2} / \mathrm{s}$, and thermal conductivity from 0.01 to $1 \mathrm{~W} /(\mathrm{mK})$. The experiments were carried out at a controlled temperature of $40{ }^{\circ} \mathrm{C}$, where $2.5 \mathrm{ml}$ of cutting oil was deposited on the equipment, using $5 \mathrm{ml}$ sterile syringes. Oils with graphene mixtures were homogenized before testing.

The wettability represents the contact conditions between a solid surface and a liquid through the action of cohesion and adhesion forces, forming a contact angle, where the lower the angle, the greater will be the wettability of the liquid [33]. With the wettability test, the characteristic adhesion and spreading of the fluids on a solid surface with low surface roughness is measured. For the wettability tests, the Krüss easy drop goniometer was used. The test consisted of depositing a drop of $10 \mu \mathrm{l}$ of cutting oil on an AISI 1045 steel sample with average surface roughness less than $0.050 \mu \mathrm{m}$, with the dynamic angle measurement being carried out at intervals of 0.2 seconds. In this kind of test, reactions between liquid and solid, the atmosphere, time, and temperature can all influence the results [34].

\subsection{Progressive load reciprocate sliding tests}

The evaluation of the friction coefficient of the tribological pair with and without the lubricating oils was carried out using progressive load reciprocate sliding tests at a frequency of $2 \mathrm{~Hz}$, amplitude of $10 \mathrm{~mm}$, and incremental loading of $6.867 \mathrm{~N}$ at 10 -minute intervals. A droplet of $0.5 \mu \mathrm{l}$ was placed in the contact region between the substrate at every load increase. The workpiece surface had an average roughness of less than $0.050 \mu \mathrm{m}$, and a carbide sphere of 5 $\mathrm{mm}$ in diameter was used as a counter body. The tests were completed 5 minutes after the lubricant film broke, so the test time and applied load varied for each condition.

The tests were developed according to the standard test method for linearly reciprocating ball-on-flat sliding wear [35]. A Universal Plint ${ }^{\circledR}$ Tribometer model TE67 was used, manufactured by Plint \& Partners LTD (Fig. 4). This equipment has a load cell similar to that described in reference [36] for monitoring tangential and normal forces. A linear variable differential transformer (LVDT) sensor, model RS 646 - 511, was used to measure the position of the counter body during the tests. The LVDT and load cell data were collected at an acquisition rate of $4 \mathrm{kHz}$. To ensure reliability, three repetitions were performed for all tests. The wear tracks were analyzed by scanning electron microscopy using secondary electrons (SEM-SE) and laser interferometry scanning (Fig. 4c).

\subsection{Milling Experiments}

The results obtained from the tribological tests were compared with the ramp milling tests results. A CNC machining center was used in these tests manufactured by Cincinnati Milacron, model Arrow 500, with $5.5 \mathrm{~kW}$ of power and a maximum rotation speed of $6000 \mathrm{rpm}$. This machining center was adapted as an open tribometer and equipped with a table dynamometer manufactured by Kistler Instruments AG, model 9272, to measure machining forces in ramp milling, as shown in Fig. 5.

The machining conditions used in the test are summarized in Table 2. TiAlN coated cemented carbide inserts with AOMT123608PEER-M VP15TF specifications from the manufacturer Mitsubishi Materials (Fig. 5c) were used as counter bodies. These inserts have a cutting edge length of $12 \mathrm{~mm}$, a cutting radius of $0.8 \mathrm{~mm}$, rake angle of $11^{\circ}$, and are recommended for machining steel in general. The inserts were attached to a $25 \mathrm{~mm}$ diameter tool holder, with $90^{\circ}$ of approach angle, having an ISO 13399 designation or Mitsubishi Materials description 
APX3000R253SA25SA (Fig. 5d). The tool holder had a capacity for three inserts; however, only one was used during the tests.

In Fig. 5a, the positioning of the two nozzles of the MQL spray system is illustrated, one on the entrance of the tool in the workpiece and the other at $90^{\circ}$ from the first. The two nozzles are approximately $15 \mathrm{~mm}$ apart from the cutting edge. To simulate the progressive load reduction in the milling trials, a path on a flat surface for $26 \mathrm{~mm}$ with a depth of $100 \mu \mathrm{m}$ was used to ramp for an additional $100 \mathrm{~mm}$ to zero depth, as illustrated in Fig. 5b. The workpiece surface was planned before each ramp milling to guarantee the same initial conditions for each test.

To avoid contamination, ethanol was used to clean the workpiece before each test and on the fluid delivery system when changing lubricants. To guarantee the test results reliability, three repetitions were performed for each cutting condition, with the tool being changed at the end of the repetitions for any indication of wear. Table 2 shows the general conditions of the test. In addition, the flood condition was carried out with the emulsifiable fluid VASCO 1000, at a concentration of $5 \%$, was also tested for comparisons.

Table 2

- Cutting parameters for the open-tribometer tests.

Fixed input parameters
Work Material: AISI 1045 normalized steel with $100 \mathrm{~mm}$ of width, $130 \mathrm{~mm}$ of length, and $10 \mathrm{~mm}$ of height.
Radial depth of cut $\left(\mathrm{a}_{\mathrm{e}}\right): 1.0 \mathrm{x} \mathrm{DC}$ (cutter diameter $\left.=25 \mathrm{~mm}\right)$
Axial depth of cut $\left(\mathrm{a}_{\mathrm{p}}\right): 100 \mu \mathrm{m}$ - to zero
Cutting speed $\left(\mathrm{v}_{\mathrm{c}}\right): 200 \mathrm{~m} / \mathrm{min}$
Feed rate $\left(\mathrm{f}_{\mathrm{z}}\right): 0.1 \mathrm{~mm} / \mathrm{tooth}$
Flow rate of the cutting fluid in MQL: $45 \mathrm{ml} / \mathrm{h}$
Air pressure of the MQL: $6 \mathrm{bar}$
MQL equipment: Bielomatik B1-210
Lubri-cooling conditions
1- Dry
2- Flood cooling with 39.52 ml/s
3- MQL with MQL14, MQL15, and LB1000 oils
4- MQL with MQL14, MQL15, and LB1000 oils with the addition of $0.05 \%$ wt. of Graphene
5- MQL with MQL14, MQL15, and LB1000 oils with the addition of $0.1 \% w t$. of Graphene

The surface roughness was measured with a portable Time Group Inc profiler, model TR220, and resolution of 0.01 $\mu \mathrm{m}$. In addition, the absolute average roughness parameter $\left(R_{a}\right)$ was measured according to NBR ISO 4288 (2008) guidelines on the ramp surfaces. Four measurements were also performed on the initial $26 \mathrm{~mm}$ of the workpiece, where the tool traveled horizontally (Fig. 5b).

\section{Results And Discussion}




\subsection{Fluid characterization}

To simplify the graphical representation, the name of the cutting fluid plus $0.05 \mathrm{G}$ was used as nomenclature for the proportion of $0.05 \%$ wt. graphene and $0.1 \mathrm{G}$ for the proportion of $0.1 \% \mathrm{wt}$.

As illustrated in Fig. 6, vegetable-based cutting oils (LB1000 and MQL15) showed higher viscosities compared to mineral-based oil, approximately $45.37 \%$ for kinematic viscosity (Fig. 6a) and $48.54 \%$ for dynamic viscosity (Fig. 6b), with the commercial oil, LB1000 being the most viscous among the samples, regardless the presence of graphene particles. Noteworthy is that the graphene particles slightly increase viscosity in the vegetable oils as their proportion was increased. In this case, there is an increase in adhesion forces and a decline in molecular movement. This condition is consistent with the research results involving graphene and other nanoparticles suspended in cutting fluids $[37,38]$. On the contrary, in the mineral-based oil MQL14, the opposing result was found, i.e., the viscosity decreased slightly with graphene addition. The decrease in viscosity with graphene in the mineral-based fluid can be explained by the graphene sheets stacking nature, altering van der Waals forces, and increasing the mineral's adjacent molecular movement. Mineral-based fluids are not polar like vegetable oils [37].

These changes were compared using ANOVA (Table 3 ) and Tukey tests considering 95\% confidence level, which proved the increase in the kinematic and dynamic viscosity for vegetable oils and the decrease in mineral oil.

Table 3

- ANOVA for kinematic viscosity and dynamic viscosity.

\begin{tabular}{|c|c|c|c|c|c|c|}
\hline \multicolumn{7}{|c|}{ Kinematic Viscosity } \\
\hline & Sum of Squares & $D F$ & Mean Square & F Value & $p$-value & F critical \\
\hline Model & 1607,735 & 8 & 200,966 & 140533,1 & 0,000 & 2,208 \\
\hline Error & 0,051 & 36 & 0,0014 & & & \\
\hline Total & 1607,787 & 44 & & & & \\
\hline \multicolumn{7}{|c|}{ Dynamic Viscosity } \\
\hline & Sum of Squares & $D F$ & Mean Square & F Value & $p$-value & F critical \\
\hline Model & 1463,285 & 8 & 182,91 & 162244,4 & 0,000 & 2,208 \\
\hline Error & 0,04 & 36 & 0,0011 & & & \\
\hline Total & 1463,326 & 44 & & & & \\
\hline
\end{tabular}

Concerning thermal conductivity (Fig. 7a), the vegetable-based oils showed, on average, $34.16 \%$ greater heat transfer capacity as compared to the mineral-based oil MQL14, regardless of the addition of graphene. Furthermore, the gradual increase of graphene in vegetable-based oils increased the thermal conductivity slightly, as expected and confirmed by ANOVA and the Tukey test with a $95 \%$ confidence interval (Table 4 and Table 5).

With the help of ANOVA, it was found that the addition of graphene particles leads to a slight decrease in the thermal diffusivity of the vegetable-based oil LB1000. However, there is an average difference of approximately $40.46 \%$ (Fig. 7b) of the thermal diffusivity between the vegetable-based oils (MQL15 and LB1000) and the mineral-based oil (MQL14) regardless of the addition of graphene. 
Table 4

- ANOVA for diffusivity and conductivity thermal.

\begin{tabular}{|c|c|c|c|c|c|c|}
\hline \multicolumn{7}{|c|}{ Thermal Diffusivity } \\
\hline & Sum of Squares & $D F$ & Mean Square & F Value & $p$-value & F critical \\
\hline Model & 5,455 & 8 & 0,681 & 142,653 & 0,000 & 2,115 \\
\hline Error & 0,258 & 54 & 4,70E-03 & & & \\
\hline Total & 5,713 & 62 & & & & \\
\hline \multicolumn{7}{|c|}{ Thermal Conductivity } \\
\hline & Sum of Squares & $D F$ & Mean Square & F Value & $p$-value & F critical \\
\hline Model & 1,771 & 8 & 0,221 & 14948,8 & 0,000 & 2,118 \\
\hline Error & $7,85 \mathrm{E}-04$ & 53 & $1,48 \mathrm{E}-05$ & & & \\
\hline Total & 1,771 & 61 & & & & \\
\hline
\end{tabular}

Table 5 presents the Tukey test between pairs for oils that did not show statistical variations with a $95 \%$ confidence interval.

Table 5

- Tukey test for diffusivity and conductivity thermal.

\begin{tabular}{|c|c|c|c|c|}
\hline \multicolumn{5}{|l|}{ Tukey test } \\
\hline \multirow[t]{2}{*}{ Pairs } & \multicolumn{2}{|c|}{ Thermal Conductivity } & \multicolumn{2}{|c|}{ Thermal Diffusivity } \\
\hline & Mean Difference & $p$-value & Mean Difference & $p$-value \\
\hline LB1000-0,1G / LB1000-0,05G & & & 0,033 & $>0,05$ \\
\hline MQL15 / LB1000-0,05G & & & 0,014 & $>0,05$ \\
\hline MQL15 / LB1000-0,1G & & & $-0,018$ & $>0,05$ \\
\hline MQL15-0,05G / LB1000 & $-0,001$ & $>0,05$ & & \\
\hline MQL15-0,05G / LB1000-0,05G & & & $-0,026$ & $>0,05$ \\
\hline MQL15-0,05G / LB1000-0,1G & & & $-0,059$ & $>0,05$ \\
\hline MQL15-0,05G / MQL15 & & & $-0,040$ & $>0,05$ \\
\hline MQL15-0,1G / LB1000 & & & & \\
\hline MQL15-0,1G / LB1000-0,05G & & & 0,006 & $>0,05$ \\
\hline MQL15-0,1G / LB1000-0,1G & & & $-0,027$ & $>0,05$ \\
\hline MQL15-0,1G / MQL15 & & & $-0,008$ & $>0,05$ \\
\hline MQL15-0,1G / MQL15-0,05G & & & 0,032 & $>0,05$ \\
\hline MQL14-0,05G / MQL14 & & & 0,024 & $>0,05$ \\
\hline MQL14-0,1G / MQL14 & & & $-0,025$ & $>0,05$ \\
\hline MQL14-0,1G / MQL14-0,05G & & & $-0,049$ & $>0,05$ \\
\hline
\end{tabular}

Page $7 / 28$ 
The results of the wettability measurement angle are presented in Fig. 8a. The contact angles of pure vegetablebased oils LB1000 and MQL15 (without the addition of graphene) stabilized with relative values in the last 50 measurement points (averages of $12.33^{\circ}$ and $11.07^{\circ}$, respectively for each fluid). On the other hand, MQL14 mineralbased oil had a low contact angle of $1.53^{\circ}$, indicating a much higher wettability. The p-values in Table 6 show the average difference between pure fluids with a $95 \%$ confidence interval. When statistically analyzing all cutting fluids, it concludes that only the wettability of pure MQL15 and LB1000-0.1G fluids are equal in the last 50 measurement points (Fig. 8b).

Table 6

- Tukey test for pure fluids LB1000, MQL15 and MQL14.

\begin{tabular}{|lll|}
\hline Peer comparison & \multicolumn{2}{l|}{ Tukey test for wettability of pure fluids } \\
\cline { 2 - 4 } & Mean difference & $\rho$-value \\
\hline MQL15 / LB1000 & $-1,2540$ & 0,000 \\
\hline MQL14 / LB1000 & $-10,7881$ & 0,000 \\
\hline MQL14 / MQL15 & $-9,5340$ & 0,000 \\
\hline
\end{tabular}

As illustrated in Fig. 8b, according to ANOVA (Table 7) (95\% of confidence interval), there was no significant difference of wettability between the vegetable-based cutting oils with the use of graphene sheets with 5 seconds of experiments. However, there are significant differences in mineral-based oil (MQL14), with an average increase of $62.88 \%$ for oil with $0.05 \%$ wt graphene and $38.10 \%$ for $0.1 \%$ wt graphene, representing a decrease in fluid wettability. 
Table 7

- ANOVA for pure fluids MQL14, MQL15, and LB1000 with 5 seconds in experiments.

\begin{tabular}{|c|c|c|c|c|c|c|}
\hline \multicolumn{7}{|c|}{ Fluids MQL14 } \\
\hline & Sum of Squares & $D F$ & Mean Square & F Value & p-value & F critical \\
\hline Model & 405,226 & 2 & 202,613 & 60,629 & 0,000 & 3,354 \\
\hline Error & 90,228 & 27 & 3,341 & & & \\
\hline Total & 495,455 & 29 & & & & \\
\hline \multicolumn{7}{|c|}{ Fluids MQL15 } \\
\hline & Sum of Squares & $D F$ & Mean Square & F Value & $p$-value & F critical \\
\hline Model & 25,093 & 2 & 12,546 & 2,499 & 0,099 & 3,327 \\
\hline Error & 145,591 & 29 & 5,02 & & & \\
\hline Total & 170,684 & 31 & & & & \\
\hline \multicolumn{7}{|c|}{ Fluids LB1000 } \\
\hline & Sum of Squares & $D F$ & Mean Square & F Value & $p$-value & F critical \\
\hline Model & 10,27 & 2 & 5,135 & 1,931 & 0,177 & 3,633 \\
\hline Error & 42,531 & 16 & 2,658 & & & \\
\hline Total & 52,801 & 18 & & & & \\
\hline
\end{tabular}

\subsection{Reciprocate sliding tests}

In Fig. 9, the tribological maps of the progressive load reciprocate sliding tests are presented for both dry and lubricated conditions with the LB1000, MQL15, and MQL14 fluids without the addition of graphene. Under all conditions, the cutting oils resulted in significant reductions in the average coefficient of friction (COF), even during the initial running-in period, where the tribosystem is still in a transient state. The running-in period is usually attributed to oxidized regions, impurities, and initial roughness of the sample $[39,40]$, with the improvements in this tribosystem indicating the potential of these fluids as boundary lubricants.

For all conditions evaluated in Fig. 9, electrical contact potential was high in the initial cycles due to the running-in period $[41,42]$. After stabilizing the tribofilm, also called steady-state, the film was broken in about 2000 cycles for the dry test. Contrary to expectations, this resulted in a decrease in the friction coefficient. The lubricating film's presence resulted in a relatively null electrical contact potential after the running-in period for the lubricated tests. It is noteworthy that the LB1000 fluid presented considerably fewer contact peaks related to momentary breaks in the tribofilm, probably due to the stick-slip phenomenon [42].

With the aid of ANOVA and 95\% of confidence interval (Table 8), it was observed that the addition of graphene sheets to the cutting oils LB1000 and MQL14 neither reduced the friction coefficient (COF) (Fig. 10a) nor the electrical contact potential (POT) (Fig. 10b). It did not increase the number of cycles (Fig. 10c) supported in the tests. However, in the vegetable-based MQL15, graphene sheets reduced the COF, resulting in more cycles that provided more significant support for loads and lower COF than LB1000. Amazingly, the mineral-based oil MQL14 (with and without graphene) exceeded 40,000 programmed cycles and a force of $116.74 \mathrm{~N}$. 
Table 8

- p-value for all fluids.

\begin{tabular}{|c|c|c|c|c|}
\hline \multicolumn{5}{|c|}{ p-value for experimental conditions } \\
\hline Experiment conditions & Maximum force & COF & POT & Cycles \\
\hline MQL15 fluids & 0,578 & 0,004 & 0,988 & 0,798 \\
\hline MQL14 fluids & & 0,838 & 0,268 & \\
\hline LB1000 fluids & 0,125 & 0,678 & 0,496 & 0,173 \\
\hline
\end{tabular}

Figure 11 shows the 3D profiles of the wear tracks of the workpiece samples. This profile was obtained through the topographic mapping, using secondary electrons during the analysis within the scanning electron microscopy (SEM). Table 9 shows the average forces achieved in these tests. In the dry tests, the flattening and the occurrence of craters along the track are evidenced by the layers' surface's depletion, broken by the friction against the carbide sphere (counter body). This phenomenon was observed even when a minute force of $13.73 \mathrm{~N}$ was applied, and the test being interrupted at only 4816 cycles.

Similar to dry tests, flattening, detachment, lateral displacement, and craters formation are observed in the wear tracks made with the vegetable-based cutting oils (MQL15 and LB1000). These fluids, however, allowed the tests to be conducted for a more significant number of cycles before the friction coefficient showed a considerable increase (Fig. 10c). This increase in COF at the end of the tests explains why the final wear marks' topography presented aspects similar to the dry tests. The MQL14 fluid did not show a peak friction coefficient even at the end of the tests, evidenced by the more homogeneous wear track aspect. Lower contact stresses can explain this homogeneous aspect from the relatively low friction coefficient throughout the test.

Table 9

- Average maximum forces applied during the progressive load reciprocate sliding tests.

\begin{tabular}{|c|c|c|c|c|c|c|c|c|c|c|}
\hline & Dry & $\begin{array}{l}\text { LB1000 } \\
\text { Pure }\end{array}$ & $\begin{array}{l}\text { LB1000 } \\
0.05 \\
\% w t\end{array}$ & $\begin{array}{l}\text { LB1000 } \\
0.1 \% w t\end{array}$ & $\begin{array}{l}\text { MQL15 } \\
\text { Pure }\end{array}$ & $\begin{array}{l}\text { MQL15 } \\
0.05 \\
\% w t\end{array}$ & $\begin{array}{l}\text { MQL15 } \\
0.1 \\
\% w t\end{array}$ & $\begin{array}{l}\text { MQL14 } \\
\text { Pure }\end{array}$ & $\begin{array}{l}\text { MQL14 } \\
0.05 \\
\% w t\end{array}$ & $\begin{array}{l}\text { MQL14 } \\
0.1 \\
\% \text { wt }\end{array}$ \\
\hline $\begin{array}{l}\text { Force } \\
(\mathrm{N})\end{array}$ & 13.73 & 73.25 & 73.25 & 66.38 & 86.8 & 91.56 & 89.27 & 116.74 & 116.74 & 116.74 \\
\hline
\end{tabular}

Figure 12 shows the volume of material removed (VMR) from the workpiece during the progressive load reciprocate sliding tests using the three cutting oils, determined by the laser interferometry scans. The addition of graphene sheets decreased the VMR for the MQL14 while increasing LB1000 and MQL15. These results suggest that in the MQL14 tribosystem, the graphene sheets could have presented a rolling behavior resulting in reduced contact stresses, corroborated by the smoother aspect of the surfaces indicated in Fig. 11. Conversely, in the other lubricants, the particles may have acted as abrasives, particularly at the end of the tests, increasing the worn volume.

These results were evaluated with ANOVA with a 95\% confidence interval, where the increase in the volume of material removal in reciprocating with LB1000 fluids with graphene sheets and reduction in the volume removal with 0.1 \%wt. graphene in the MQL14 fluid was observed statistically (Fig. 12b and Table 10). According to the $p$-value $(0,194)$ of Table 10 , the graphene sheets did not result in statistically variations in the volume of material removed in the MQL15 fluid. 
Table 10

- $\mathrm{p}$-value for the volume of material removed from the reciprocate tracks.

\begin{tabular}{|c|c|c|c|c|c|c|}
\hline \multicolumn{7}{|c|}{ Fluids MQL14 } \\
\hline & Sum of Squares & $D F$ & Mean Square & F Value & p-value & F critical \\
\hline Model & $1,04 \mathrm{E}+13$ & 2 & $5,20 E+12$ & 6,256 & 0,034 & 5,143 \\
\hline Error & $4,99 E+12$ & 6 & $8,32 E+11$ & & & \\
\hline Total & $1,54 \mathrm{E}+13$ & 8 & & & & \\
\hline \multicolumn{7}{|c|}{ Fluids MQL15 } \\
\hline & Sum of Squares & $D F$ & Mean Square & F Value & $p$-value & F critical \\
\hline Model & $4,10 E+13$ & 2 & $2,05 E+13$ & 2,173 & 0,194 & 5,143 \\
\hline Error & $5,65 E+13$ & 6 & $9,42 E+12$ & & & \\
\hline Total & $9,75 E+13$ & 8 & & & & \\
\hline \multicolumn{7}{|c|}{ Fluids LB1000 } \\
\hline & Sum of Squares & $D F$ & Mean Square & F Value & $p$-value & F critical \\
\hline Model & $6,30 E+13$ & 2 & $3,15 E+13$ & 25,702 & 0,001 & 5,143 \\
\hline Error & $7,35 E+12$ & 6 & $1,23 E+12$ & & & \\
\hline Total & $7,04 \mathrm{E}+13$ & 8 & & & & \\
\hline
\end{tabular}

\subsection{Milling ramp tests}

For all the evaluated conditions in the milling ramp tests, the ramp's central region showed a linear relationship between the evaluated forces, following the Coulomb friction model $[8,9,43]$. Therefore, after finding the region of linear friction that obeys Coulomb's law of friction, as performed by [9] and illustrated in Fig. 13, it is possible to calculate the COF on the slope region between the tool and the workpiece, by Eq. (1) [11], where $a$ is the side rake angle.

The machining force (FU) was calculated using Eq. (2) [44] with the measurement of the cutting force $\left(F_{c}\right)$, feed force $\left(F_{f}\right)$, and passive force $\left(F_{p}\right)$ by the Kistler dynamometer.

$$
\frac{\sum{ }_{1}^{\eta} \mu n=\tan \left(\alpha+\tan ^{-1}(F N / F T)\right)}{n}
$$

1

$$
F U=\sqrt{F_{c}^{2}+F_{f}^{2}+F_{a p}^{2}}
$$


Figure 14 shows the results of the machining forces (FU) and the friction coefficient (COF) for the various lubricooling conditions used. The dry cut showed high COF and low FU. This result can be explained based on the friction and the heat generated in the cutting zone, which reduces the shear resistance of the material. Contrarily, when the cut is performed under low-pressure flood cooling conditions, the high amount of cutting oil lubricates while dissipating the heat generated in the cutting zones, resulting in low COF and high FU.

Corroborating with the results of the tribological reciprocating sliding tests presented in Sect. 3.2, the milling tests with the MQL15 and MQL14 oils (pure and with graphene additions) showed lower COF. However, the FU was relatively higher than when using the cutting oil LB1000, with the lower heat generation's probable explanation. The COF values determined by the open tribometer tests are higher because they represent the conditions closest to the actual machining, where the chip speed and the load at the machining interfaces are higher. Furthermore, even using 6 bar air pressure in the MQL system, it is not guaranteed that the lubricant will fully reach the machining interfaces to the point of fully forming the tribofilm, a condition guaranteed in the experiments with conventional tribometer (reciprocating tests), where a micro drop of fluid was placed between the tribological pair, guaranteeing a film of fluid from the beginning of the experiment until its rupture. These results are expressive and corroborate with the results obtained by [9], which indicated the reciprocating sliding tests' potential to represent the machining tribosystem under conditions of low depth of cut.

The surface roughness results of the milling ramp tests are shown in Fig. 15. The addition of graphene sheets to the oils contributed to the decrease of the $\mathrm{R}_{\mathrm{a}}$ parameters in the experiments, mainly with the dispersion of $0.1 \% \mathrm{wt}$. This decrease can be explained by increasing nanoparticle concentration and the degree of chemical interaction between the particles and the newly formed surface, which increases the protective film between the tribological pairs, consequently increasing the surface quality [45]. According to ANOVA and Tukey's test (95\% of confidence interval) shown in Table 11, there were significant differences in the $R_{a}$ of the vegetable cutting fluids and mineral fluid and the dispersion of graphene sheets compared to pure fluids. 
Table 11

- p-value and comparison between pairs of surface roughness $\left(R_{a}\right)$ of ramp milling.

\begin{tabular}{|c|c|c|}
\hline \multicolumn{3}{|c|}{$p$-value of the statistical analysis of the surface roughness $\left(R_{a}\right)$} \\
\hline Experiment conditions under analysis & $p$-value & Statistically different pairs \\
\hline \multirow[t]{4}{*}{ Flood, dry and MQL15 fluids } & \multirow[t]{4}{*}{0,000} & MQL15 > flood \\
\hline & & MQL15 > dry \\
\hline & & MQL15 > MQL15-0,05G \\
\hline & & MQL15 > MQL15-0,1G \\
\hline \multirow[t]{2}{*}{ Flood, dry and MQL14 fluids } & \multirow[t]{2}{*}{$5,34 \mathrm{E}-03$} & MQL14 > MQL14-0,05G \\
\hline & & MQL14 > MQL14-0,1G \\
\hline \multirow[t]{3}{*}{ Flood, dry and LB1000 fluids } & \multirow[t]{3}{*}{0,000} & LB1000 > dry \\
\hline & & LB1000-0,05G > dry \\
\hline & & LB1000 > LB1000-0,1G \\
\hline
\end{tabular}

\section{Conclusions}

This study investigated changes in the thermos-physical properties of the oils, one of mineral and two of vegetablebased, with and without the addition of graphene nanosheets at proportions of $0.05 \%$ wt and $0.1 \%$ wt. In addition, the behavior of the friction coefficient determined by progressive load reciprocate sliding tests and the conditions generated in the tribosystems of the chip-tool-workpiece interfaces during the ramp milling tests with the application of the oils by MQL were also studied. The main results allowed the following conclusions to be drawn:

- When mixed with cutting oils, graphene resulted in layers of atoms forming sheets with an average thickness of $36.83 \mathrm{~nm}$.

- Graphene sheets alter the van der Waals forces and, consequently, the molecular movement of the fluids alters the thermo-physical properties of the nanofluids. Consequently, a decrease in the viscosity of the mineral fluid MQL14 and an increase in the viscosity of the vegetable-based fluids MQL15 and LB1000 were observed. Furthermore, an increase in the wettability of the mineral fluid MQL14 was also verified with the addition of graphene nanosheets, reaching $62.88 \%$ and $38.10 \%$ for the mixture with $0.05 \%$ wt and $0.1 \%$ wt of graphene, respectively. However, as noted in Sect. 3.3, this variation did not significantly change its tribological behavior but ensured a greater load capacity over time without deteriorating the formed tribofilm.

- Cutting oils with and without graphene showed better tribological behaviors in reciprocating and ramp milling tests (open tribometer) compared to the dry condition. However, the COF values determined by the reciprocating sliding tests were low compared to those determined by the machining tests. This can be explained by combining lower loads and smaller sliding distances, resulting in a tribosystem that does not fully represent the machining conditions.

- Concerning the vegetable-based oils, considered ecologically less aggressive to the environment, the MQL15 showed better lubricating properties in the milling ramp tests than the LB1000 oil, with better conditions for tribosystems chip-tool-workpiece interfaces. The MQL15 also outperformed LB1000 concerning the number of 
cycles, applied load, COF, surface roughness, and volume of material removed from the wear track in the reciprocating tests.

- The vegetable-based cutting fluids, especially with graphene nanoparticles, have a high potential to increase the machining process efficiency and the sustainability of the machining processes.

\section{Declarations}

\section{Funding}

All the authors declare that they have no funding.

\section{Conflicts of interest/Competing interests}

All the authors declare that they have no conflict of interest.

\section{Availability of data and material}

All the authors declare that this paper has no available data or material.

\section{Code availability}

All the authors declare that this paper has no available code.

\section{Authors' contributions}

The authors declare that all co-authors participated in all the development stages of this review.

\section{Ethics approval}

Not applicable to this paper.

\section{Consent to participate}

Not applicable to this paper.

\section{Consent for publication}

Not applicable to this paper.

\section{Acknowledgments}


The authors are grateful to the Brazilian research agencies CNPq, FAPEMIG and Coordenação de Aperfeiçoamento de Pessoal de Nível Superior - Brasil (CAPES) - Finance Code 001 financial support. The auhors are also gratefull for Pontifícia Universidade Católica do Paraná - PUCPR do Brazil and the Federal University of Uberlândia for their technical supports.

\section{References}

[1] R. Neugebauer, K.D. Bouzakis, B. Denkena, F. Klocke, A. Sterzing, A.E. Tekkaya, R. Wertheim, Velocity effects in metal forming and machining processes, CIRP Ann. - Manuf. Technol. 60 (2011) 627-650. doi:10.1016/j.cirp.2011.05.001.

[2] H. Puls, F. Klocke, D. Lung, Experimental investigation on friction under metal cutting conditions, Wear. 310 (2014) 63-71. doi:10.1016/j.wear.2013.12.020.

[3] S.N. Melkote, W. Grzesik, J. Outeiro, J. Rech, V. Schulze, H. Attia, P.J. Arrazola, R. M'Saoubi, C. Saldana, Advances in material and friction data for modelling of metal machining, CIRP Ann. - Manuf. Technol. 66 (2017) 731-754. doi:10.1016/j.cirp.2017.05.002.

[4] M. Akmal, K.S.E. Layegh, I. Lazoglu, A. Akgün, Ç. Yavaş, Friction Coefficients on Surface Finish of AlTiN Coated Tools in the Milling of Ti6Al4V, Procedia CIRP. 58 (2017) 596-600. doi:10.1016/j.procir.2017.03.231.

[5] W. Grzesik, J. Rech, K. Zak, Determination of friction in metal cutting with tool wear and flank face effects, Wear. 317 (2014) 8-16. doi:10.1016/j.wear.2014.05.003.

[6] V. Schulze, J. Michna, J. Schneider, P. Gumbsch, Modelling of cutting induced surface phase transformations considering friction effects, Procedia Eng. 19 (2011) 331-336. doi:10.1016/j.proeng.2011.11.121.

[7] M. Olsson, S. Söderberg, S. Jacobson, S. Hogmark, Simulation of cutting tool wear by a modified pin-on-disc test, Int. J. Mach. Tools Manuf. 29 (1989) 377-390. doi:10.1016/0890-6955(89)90007-2.

[8] J. Brocail, M. Watremez, L. Dubar, Identification of a friction model for modelling of orthogonal cutting, Int. J. Mach. Tools Manuf. 50 (2010) 807-814. doi:10.1016/j.jimachtools.2010.05.003.

[9] LRR da Silva, R.S. Ruzzi, V.C. Teles, WF Sales, WL Guesser, A.R. Machado, Analysis of the coefficient of friction at the workpiece-tool interface in milling of high strength compacted graphite cast irons, Wear. 426-427 (2019) 16461657. doi:10.1016/j.wear.2019.01.111.

[10] A. Egaña, J. Rech, P.J. Arrazola, Characterization of Friction and Heat Partition Coefficients during Machining of a TiAl6V4 Titanium Alloy and a Cemented Carbide, Tribol. Trans. 55 (2012) 665-676.

doi:10.1080/10402004.2012.692007.

[11] E. Ozlu, E. Budak, A. Molinari, Analytical and experimental investigation of rake contact and friction behavior in metal cutting, Int. J. Mach. Tools Manuf. 49 (2009) 865-875. doi:10.1016/j.ijmachtools.2009.05.005.

[12] H. Ben Abdelali, C. Claudin, J. Rech, W. Ben Salem, P. Kapsa, A. Dogui, Experimental characterization of friction coefficient at the tool-chip-workpiece interface during dry cutting of AISI 1045, Wear. 286-287 (2012) 108-115. doi:10.1016/j.wear.2011.05.030. 
[13] Á.R. Machado, J. Wallbank, The effect of extremely low lubricant volumes in machining, Wear. 210 (1997) 7682. doi:10.1016/S0043-1648(97)00059-8.

[14] YS. Liao, H.M. Lin, Mechanism of minimum quantity lubrication in high-speed milling of hardened steel, Int. J. Mach. Tools Manuf. 47 (2007) 1660-1666. doi:10.1016/J.IJMACHTOOLS.2007.01.007.

[15] R.W. Maruda, G.M. Krolczyk, S. Wojciechowski, B. Powalka, S. Klos, N. Szczotkarz, M. Matuszak, N. Khanna, Evaluation of turning with different cooling-lubricating techniques in terms of surface integrity and tribologic properties, Tribol. Int. 148 (2020) 106334. doi:10.1016/j.triboint.2020.106334.

[16] H. Singh, V.S. Sharma, M. Dogra, Exploration of Graphene assisted vegetables oil based minimum quantity lubrication for surface grinding of TI-6AL-4V-ELI, Tribol. Int. 144 (2020) 106113. doi:10.1016/j.triboint.2019.106113.

[17] J. Ji, Y. Li, W. Peng, G. Zhang, F. Zhang, X. Fan, Advanced Graphene-Based Binder-Free Electrodes for HighPerformance Energy Storage, Adv. Mater. 27 (2015) 5264-5279. doi:10.1002/adma.201501115.

[18] M. Uysal, H. Akbulut, M. Tokur, H. Algül, T. Çetinkaya, Structural and sliding wear properties of Ag/Graphene/WC hybrid nanocomposites produced by electroless co-deposition, J. Alloys Compd. 654 (2016) 185-195. doi:10.1016/j.jallcom.2015.08.264.

[19] K.-H. Park, B. Ewald, P.Y. Kwon, Effect of Nano-Enhanced Lubricant in Minimum Quantity Lubrication Balling Milling, J. Tribol. 133 (2011) 031803. doi:10.1115/1.4004339.

[20] A. Uysal, An experimental study on cutting temperature and burr in milling of ferritic stainless steel under MQL using nano graphene reinforced cutting fluid, Adv. Mater. Proc. 2 (2018) 560-563. doi:10.5185/amp/038.

[21] S. Huang, A. He, J.H. Yun, X. Xu, Z. Jiang, S. Jiao, H. Huang, Synergistic tribological performance of a water based lubricant using graphene oxide and alumina hybrid nanoparticles as additives, Tribol. Int. 135 (2019) 170180. doi:10.1016/j.triboint.2019.02.031.

[22] L. Wang, P. Gong, W. Li, T. Luo, B. Cao, Mono-dispersed Ag/Graphene nanocomposite as lubricant additive to reduce friction and wear, Tribol. Int. 146 (2020) 106228. doi:10.1016/j.triboint.2020.106228.

[23] ASTM E8/E8M, Standard Test Methods for Tension Testing of Metallic Materials, Astm Int. (2013). doi:10.1520/E0008.

[24] ASTM E92-17, Standard Test Methods for Vickers Hardness and Knoop Hardness of Metallic Materials, ASTM Int. i (2009) 3128. doi:10.1520/E0092-17.2.

[25] R.L. de Paiva, R. de Souza Ruzzi, L.R. de Oliveira, E.P. Bandarra Filho, L.M. Gonçalves Neto, R.V. Gelamo, R.B. da Silva, Experimental study of the influence of graphene platelets on the performance of grinding of SAE 52100 steel, Int. J. Adv. Manuf. Technol. 110 (2020). doi:10.1007/s00170-020-05866-x.

[26] R.T. Khare, R. V. Gelamo, M.A. More, D.J. Late, CS Rout, Enhanced field emission of plasma treated multilayer graphene, Appl. Phys. Lett. 107 (2015). doi:10.1063/1.4931626.

[27] A. Dato, V. Radmilovic, Z. Lee, J. Phillips, M. Frenklach, Substrate-free gas-phase synthesis of graphene sheets, Nano Lett. 8 (2008) 2012-2016. doi:10.1021/nl8011566. 
[28] J. Samuel, J. Rafiee, P. Dhiman, N. Koratkar, Graphene Colloidal Suspensions as High Performance SemiSynthetic, J. Phys. Chem. (2010) 3410-3415.

[29] A.C. Ferrari, J.C. Meyer, V. Scardaci, C. Casiraghi, M. Lazzeri, F. Mauri, S. Piscanec, D. Jiang, K.S. Novoselov, S. Roth, A.K. Geim, Raman spectrum of graphene and graphene layers, Phys. Rev. Lett. 97 (2006) 1-4. doi:10.1103/PhysRevLett.97.187401.

[30] Y. Hernandez, V. Nicolosi, M. Lotya, F.M. Blighe, Z. Sun, S. De, I.T. McGovern, B. Holland, M. Byrne, Y.K. Gun'ko, J.J. Boland, P. Niraj, G. Duesberg, S. Krishnamurthy, R. Goodhue, J. Hutchison, V. Scardaci, A.C. Ferrari, J.N. Coleman, High-yield production of graphene by liquid-phase exfoliation of graphite, Nat. Nanotechnol. 3 (2008) 563-568. doi:10.1038/nnano.2008.215.

[31] ASTM D445-18, Standard Test Method for Kinematic Viscosity of Transparent and Opaque Liquids (and Calculation of Dynamic Viscosity), Annu. B. ASTM Stand. (2018) 1-10. doi:10.1520/D0445-11A.In.

[32] ASTM D2270-10, Standard Practice for Calculating Viscosity Index from Kinematic Viscosity at $40{ }^{\circ} \mathrm{C}$ and 100 ${ }^{\circ} \mathrm{C}$, ASTM Int. (2016). doi:10.1520/D2270-10R16.2.

[33] A.S. Araújo Junior, W.F. Sales, RB da Silva, E.S. Costa, Á. Rocha Machado, Lubri-cooling and tribological behavior of vegetable oils during milling of AISI 1045 steel focusing on sustainable manufacturing, J. Clean. Prod. 156 (2017) 635-647. doi:10.1016/j.jclepro.2017.04.061.

[34] A.P. Luz, V.C. Pandolfelli, S. Ribeiro, Review article: Use of the wettability in the investigation of the corrosion behaviour of the refractory materials, Ceramica. 54 (2008) 174-183. doi:10.1590/S0366-69132008000200007.

[35] ASTM, G133-05 Linearly Reciprocating Ball-on-Flat Sliding Wear, Astm Int. (2016) 1-9. doi:10.1520/G013305R16.2.

[36] R.M.A. Dutra, Controle e validação de um microtribômetro instrumentado para observar a evolução da marca de desgaste via microscopia óptica, 2017.

[37] Y. Wang, C. Li, Y. Zhang, B. Li, M. Yang, X. Zhang, S. Guo, G. Liu, Experimental evaluation of the lubrication properties of the wheel/workpiece interface in MQL grinding with different nanofluids, Tribol. Int. 99 (2016) $198-210$. doi:10.1016/j.triboint.2016.03.023.

[38] X. Bai, C. Li, L. Dong, Q. Yin, Experimental evaluation of the lubrication performances of different nanofluids for minimum quantity lubrication (MQL) in milling Ti-6Al-4V, Int. J. Adv. Manuf. Technol. 101 (2019) 2621-2632. doi:10.1007/s00170-018-3100-9.

[39] C. Vergne, C. Boher, C. Levaillant, R. Gras, Analysis of the friction and wear behavior of hot work tool scale: Application to the hot rolling process, Wear. 250-251 (2001) 322-333. doi:10.1016/S0043-1648(01)00598-1.

[40] J.C.G. Milan, M.A. Carvalho, R.R. Xavier, SD. Franco, J.D.B. De Mello, Effect of temperature, normal load and preoxidation on the sliding wear of multi-component ferrous alloys, Wear. 259 (2005) 412-423.

doi:10.1016/j.wear.2005.02.050.

[41] P.J. Blau, How common is the steady-state? The implications of wear transitions for materials selection and design, Wear. 332-333 (2015) 1120-1128. doi:10.1016/j.wear.2014.11.018.

Page $17 / 28$ 
[42] MB dos Santos, H.L. Costa, J.D.B. De Mello, Potentiality of triboscopy to monitor friction and wear, Wear. (2015). doi:10.1016/j.wear.2014.10.017.

[43] W. Grzesik, K. Zak, Friction quantification in the oblique cutting with CBN chamfered tools, Wear. 304 (2013) 3642. doi:10.1016/j.wear.2013.04.020.

[44] A.R. Machado, A.M. Abrão, R.T. Coelho, M.B. Da Silva, Teoria da Usinagem dos Materiais, 3rd ed., Editora Edgard Blucher, São Paulo - SP, 2015.

[45] M. Sayuti, A.A.D. Sarhan, M. Hamdi, An investigation of optimum SiO2 nanolubrication parameters in end milling of aerospace Al6061-T6 alloy, Int. J. Adv. Manuf. Technol. 67 (2013) 833-849. doi:10.1007/s00170-012-4527-z.

\section{Figures}

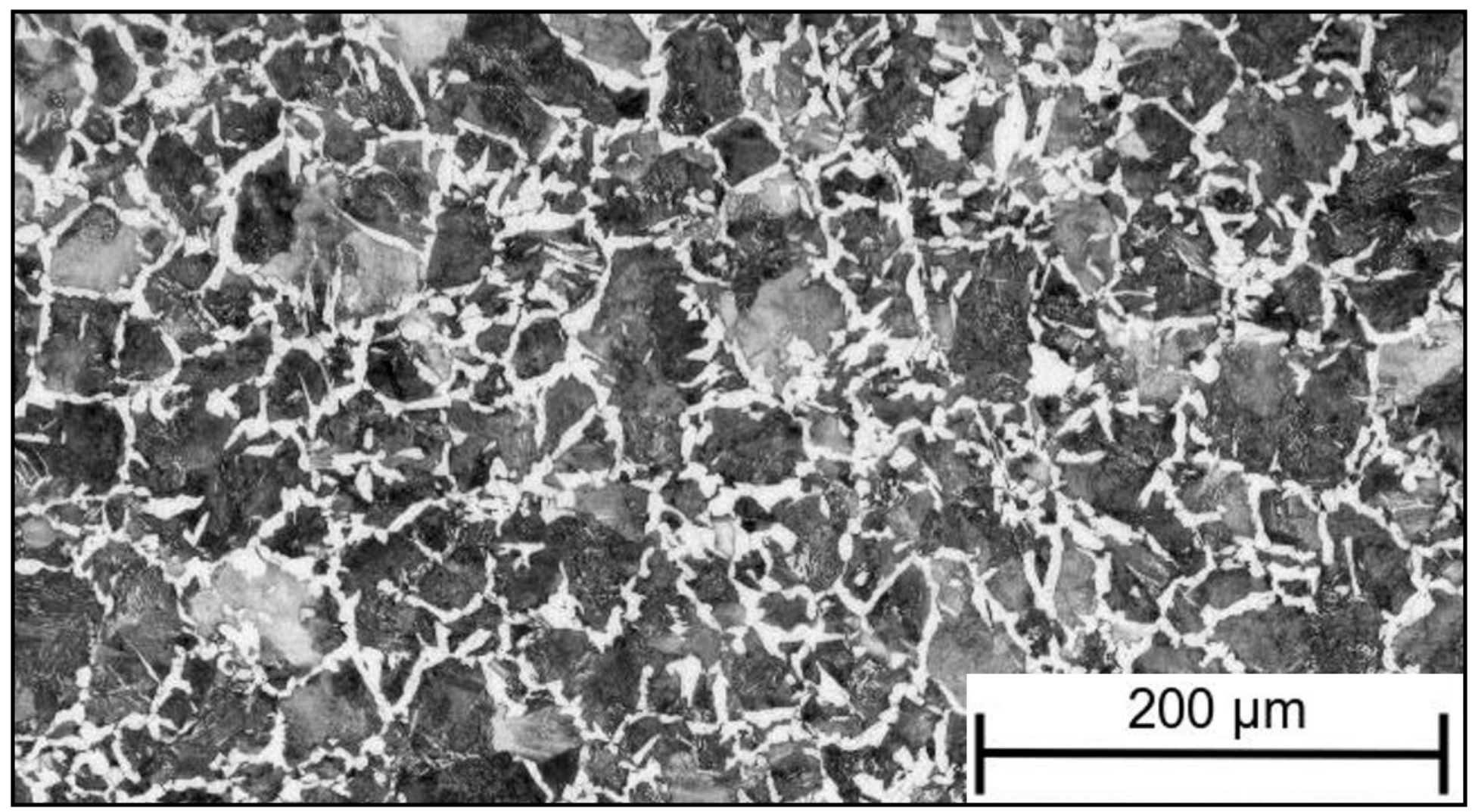

Figure 1

Microstructure of the workpiece material. 

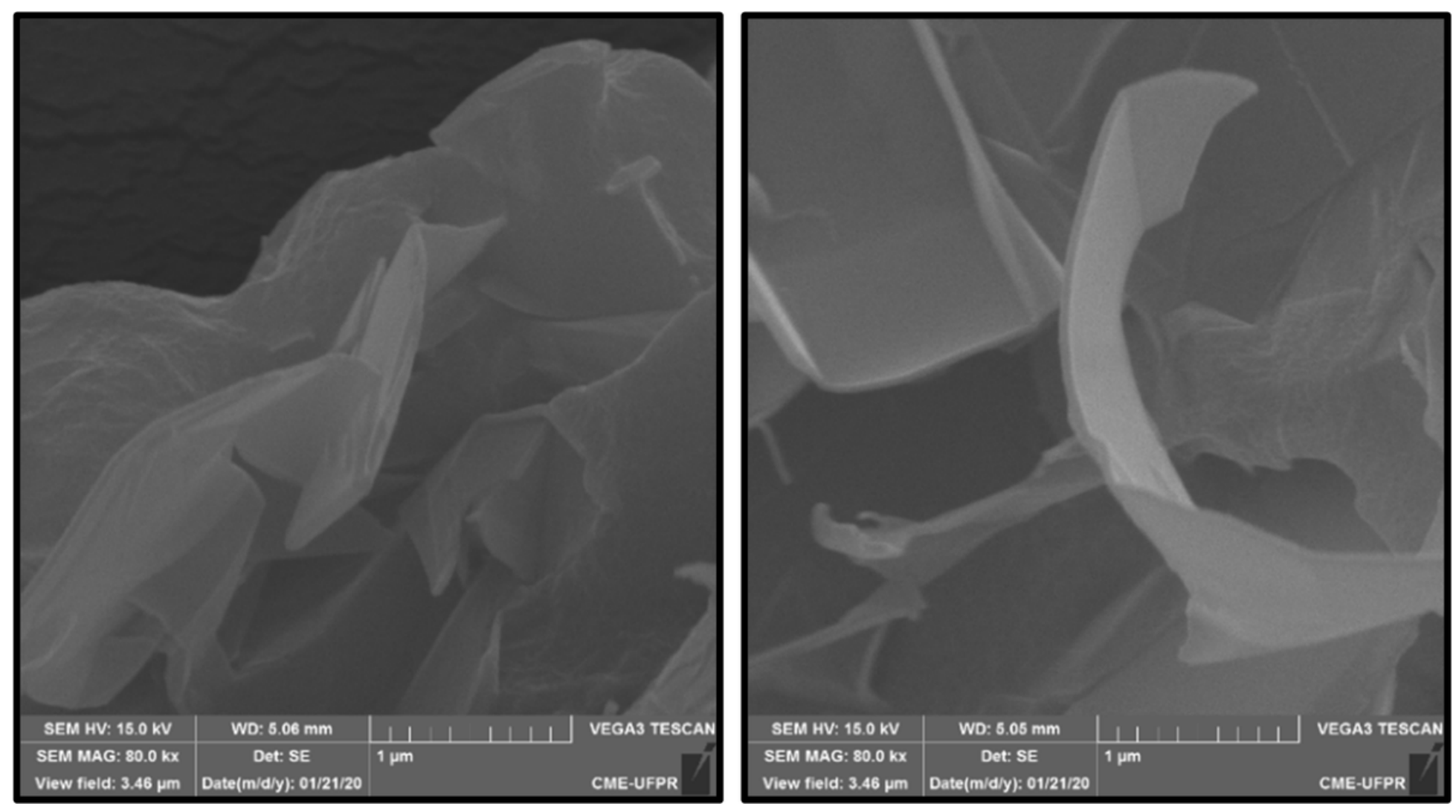

\section{Figure 2}

SEM images of the graphene sheets.
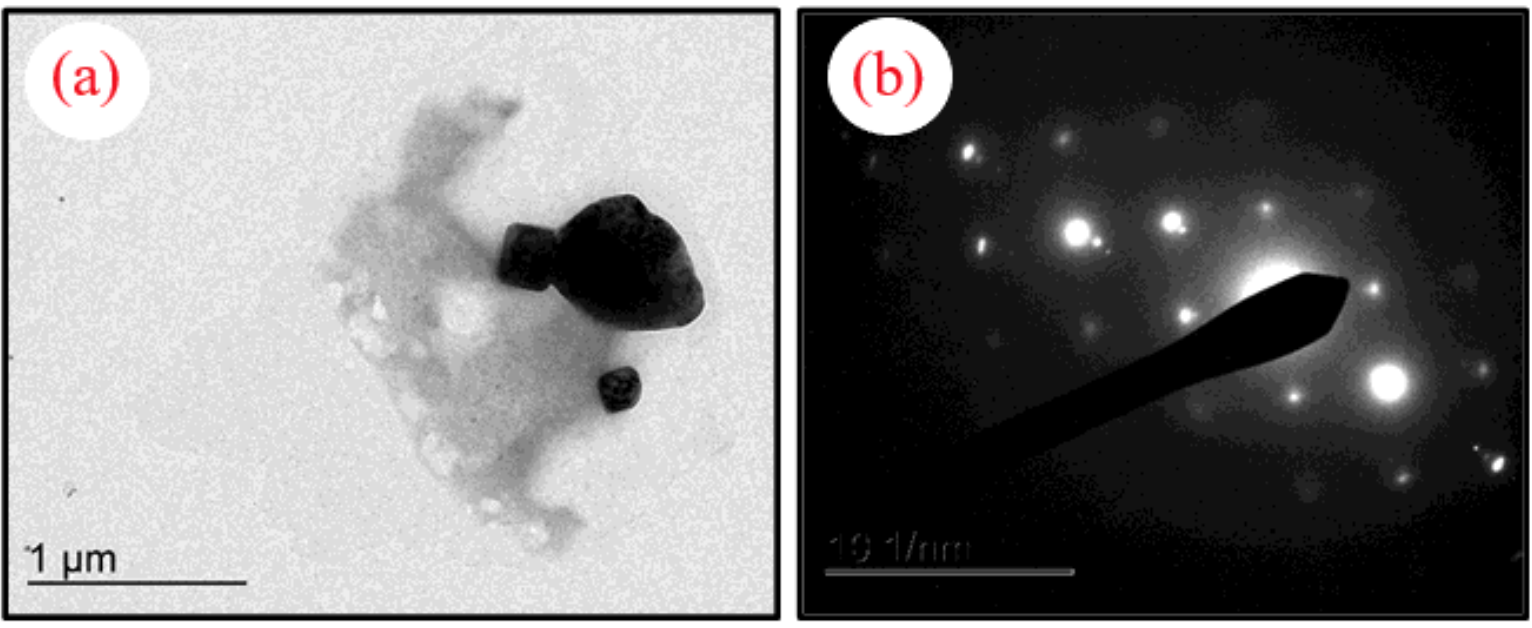

\section{Figure 3}

TEM images of the graphene particles: (a) multilayers; (b) electron diffraction of the multilayers. 

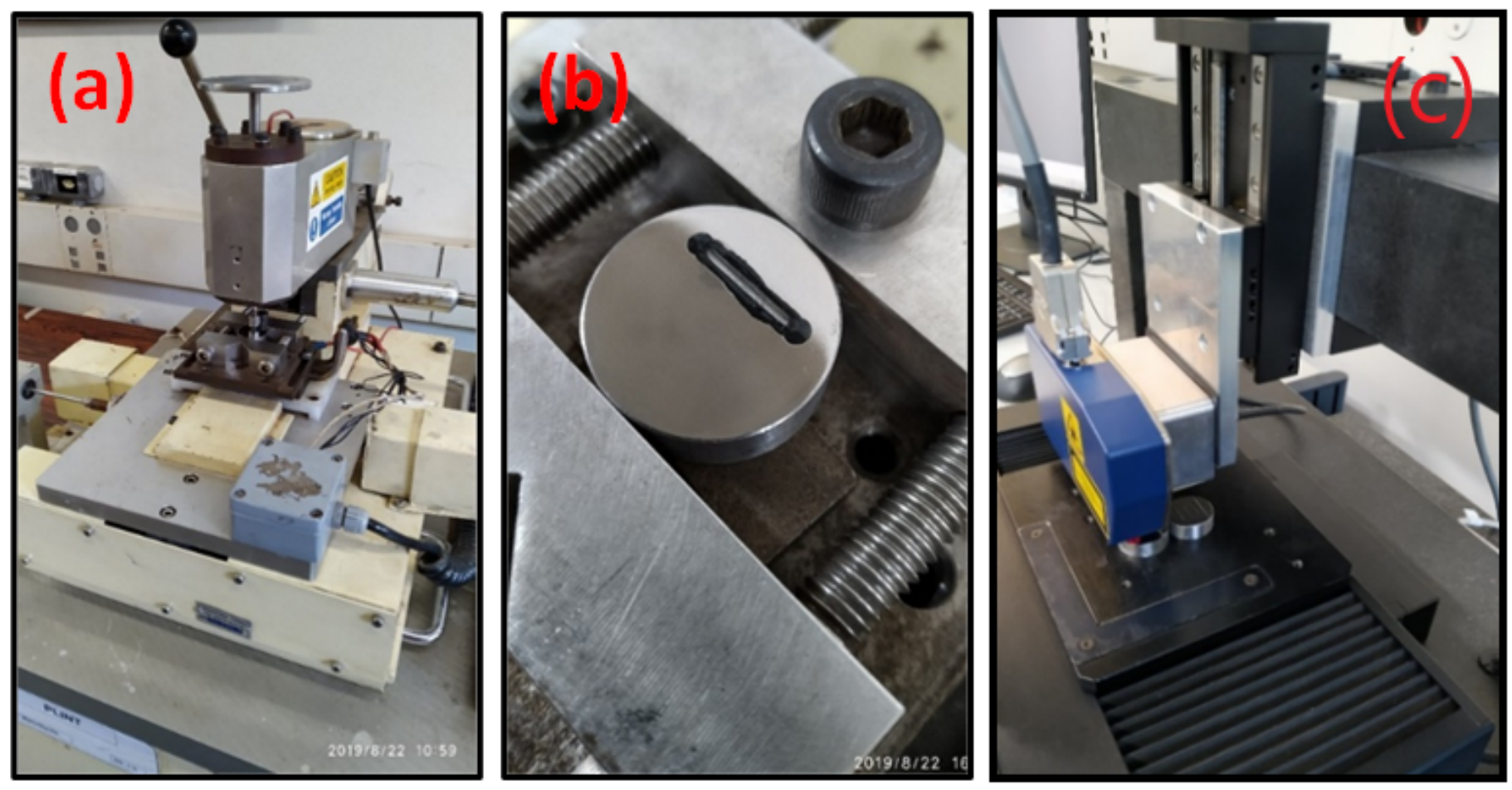

Figure 4

(a) Universal tribometer Plint ${ }^{\circledR}$ model TE67; (b) Tribometer clamping base; (c) Laser interferometer.
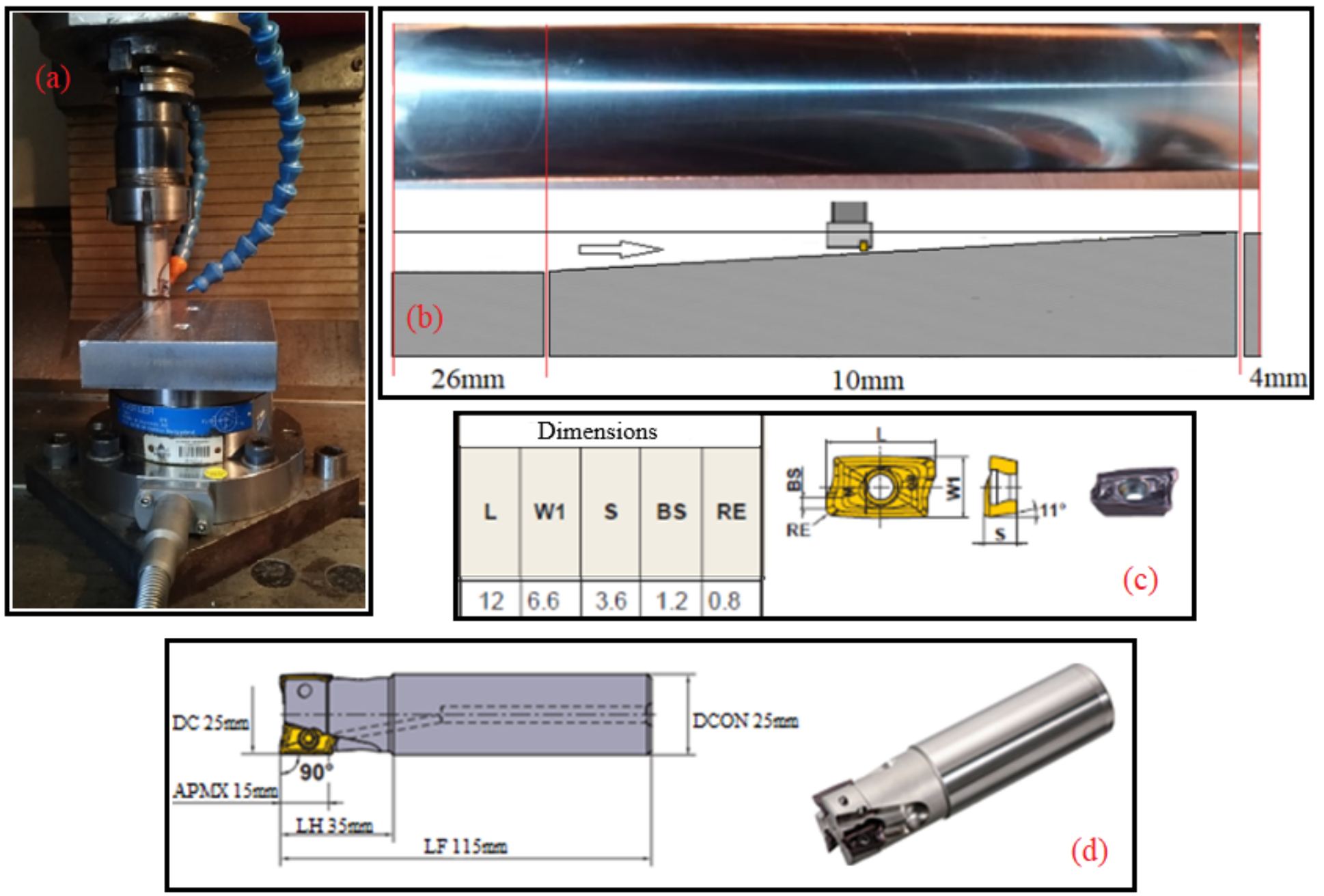
Figure 5

(a) Experimental setup showing the dynamometer workpiece, cutting tool, and fluid nozzles; (b) View of the rampmilled surface; (c) Dimensions of insert AOMT123608PEER-M; (d) Rod APX3000R253SA25SA for fixing the inserts.
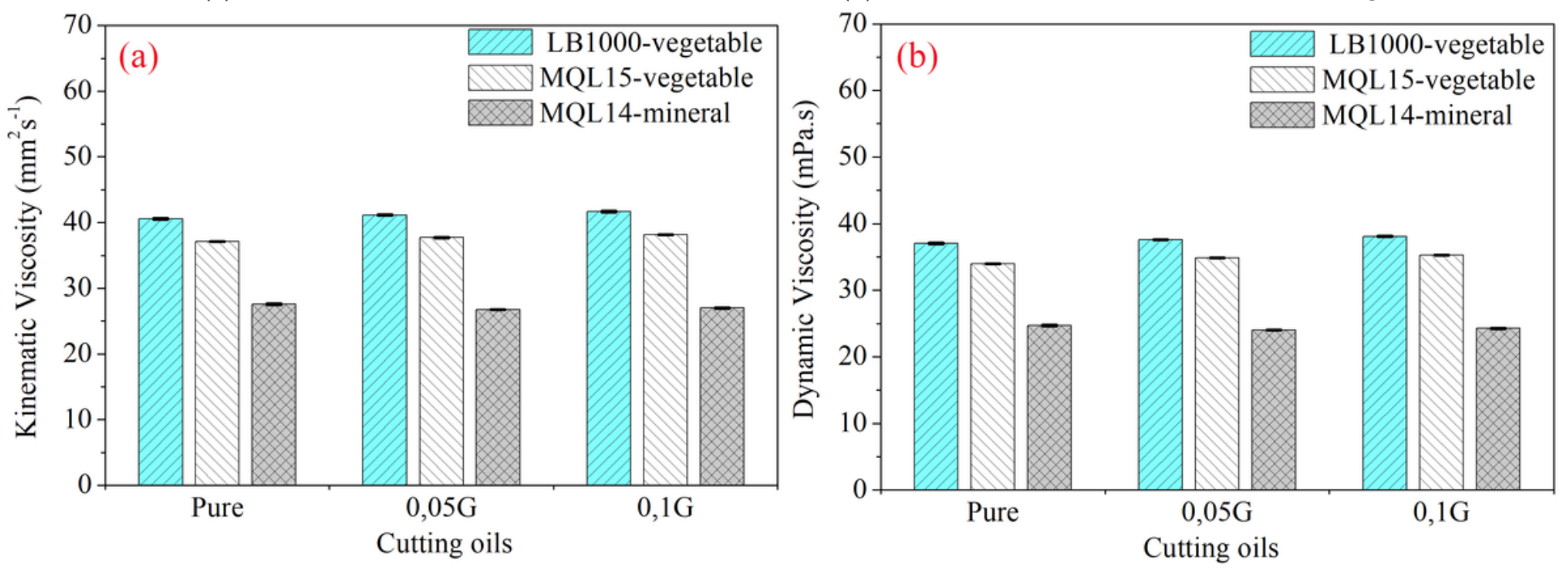

\section{Figure 6}

Kinematic and dynamic viscosity of the cutting fluids.
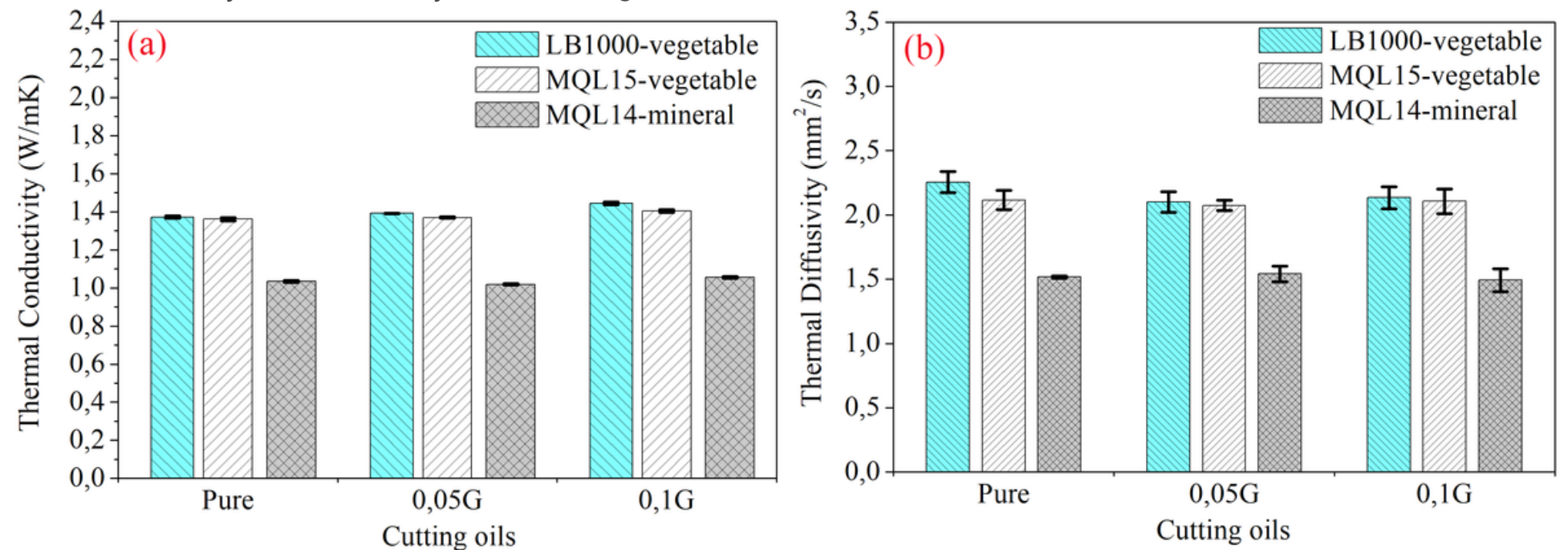

Figure 7

Thermal properties of the cutting fluids: (a) thermal conductivity; (b) thermal diffusivity. 

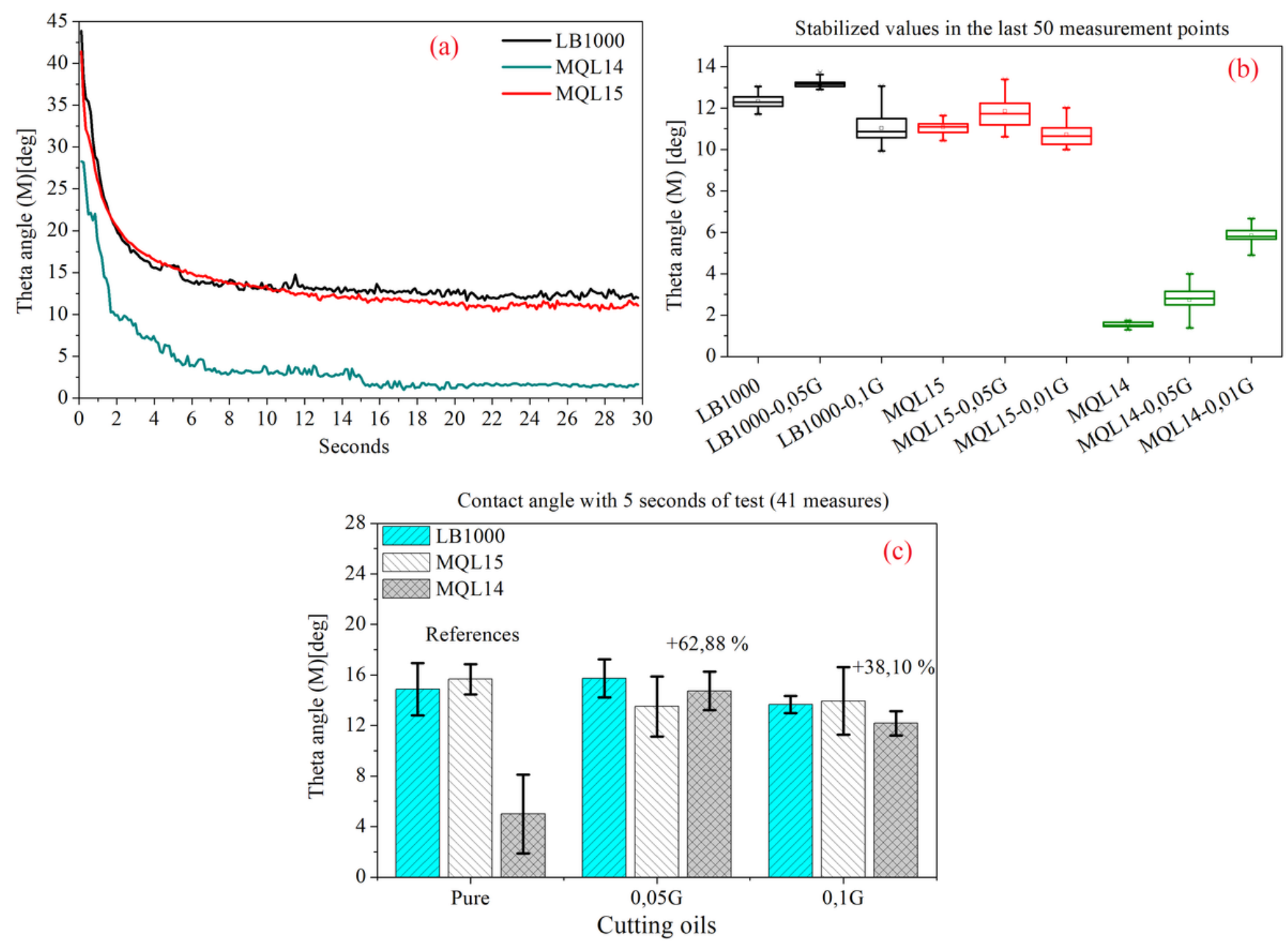

\section{Figure 8}

(a) Contact angle of the cutting oils LB1000, MQL15 and MQL14. (b) Boxplot graphs of the values established in the last 50 measurement points. (c) The contact angle of all cutting oils at 5 seconds of the test. 

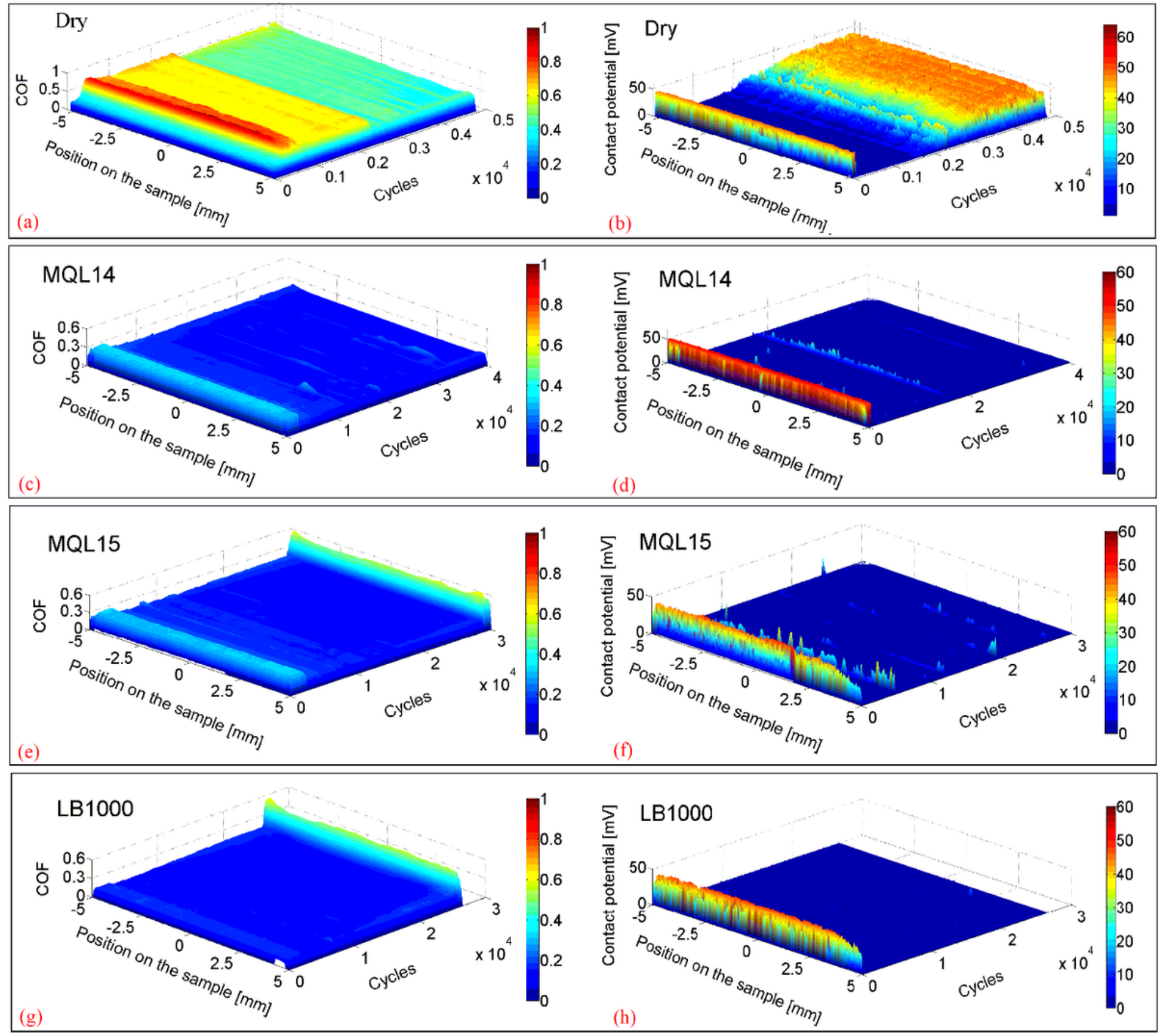

\section{Figure 9}

Triboscopy maps of the reciprocating sliding tests with progressive loads for the several lubri-cooling conditions tested (a-b) dry, (c-d) pure MQL14, (e-f) pure MQL15, and (g-h) pure LB1000. 


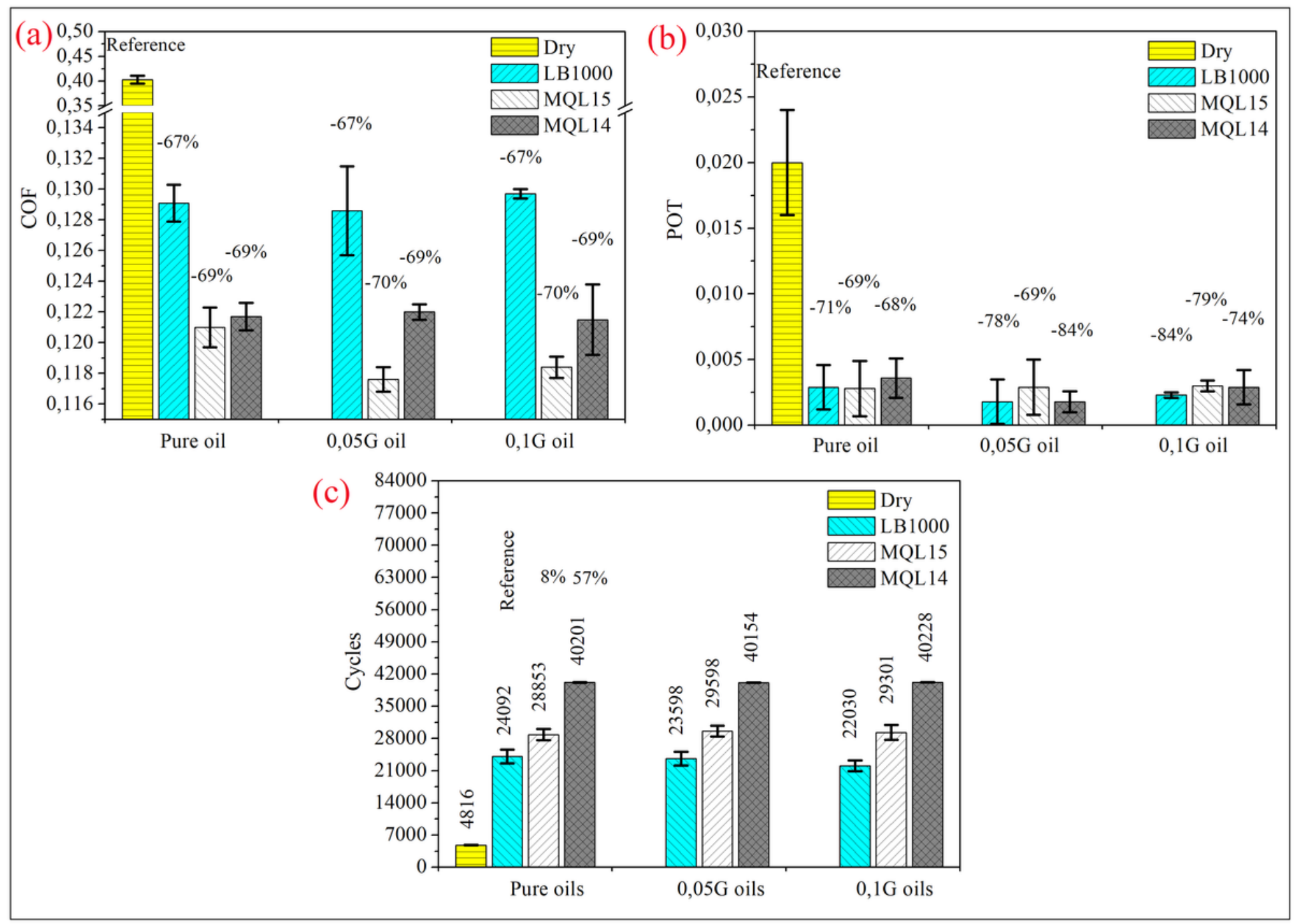

\section{Figure 10}

General results of the reciprocating sliding tests with progressive loads: (a) Coefficient of friction (COF); (b) Contact potential (POT); (c) the number of cycles supported by the oil film. 

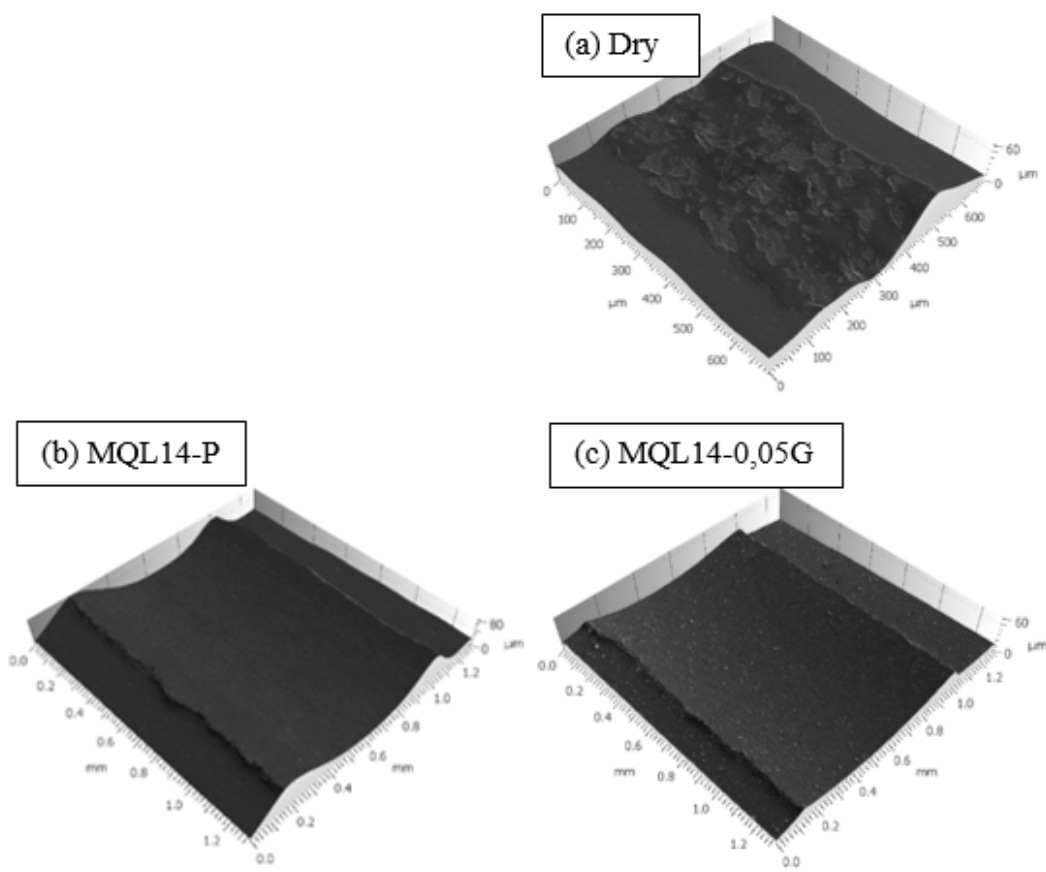

$$
\text { (c) MQL14-0,05G }
$$

(d) MQL14-0,1G
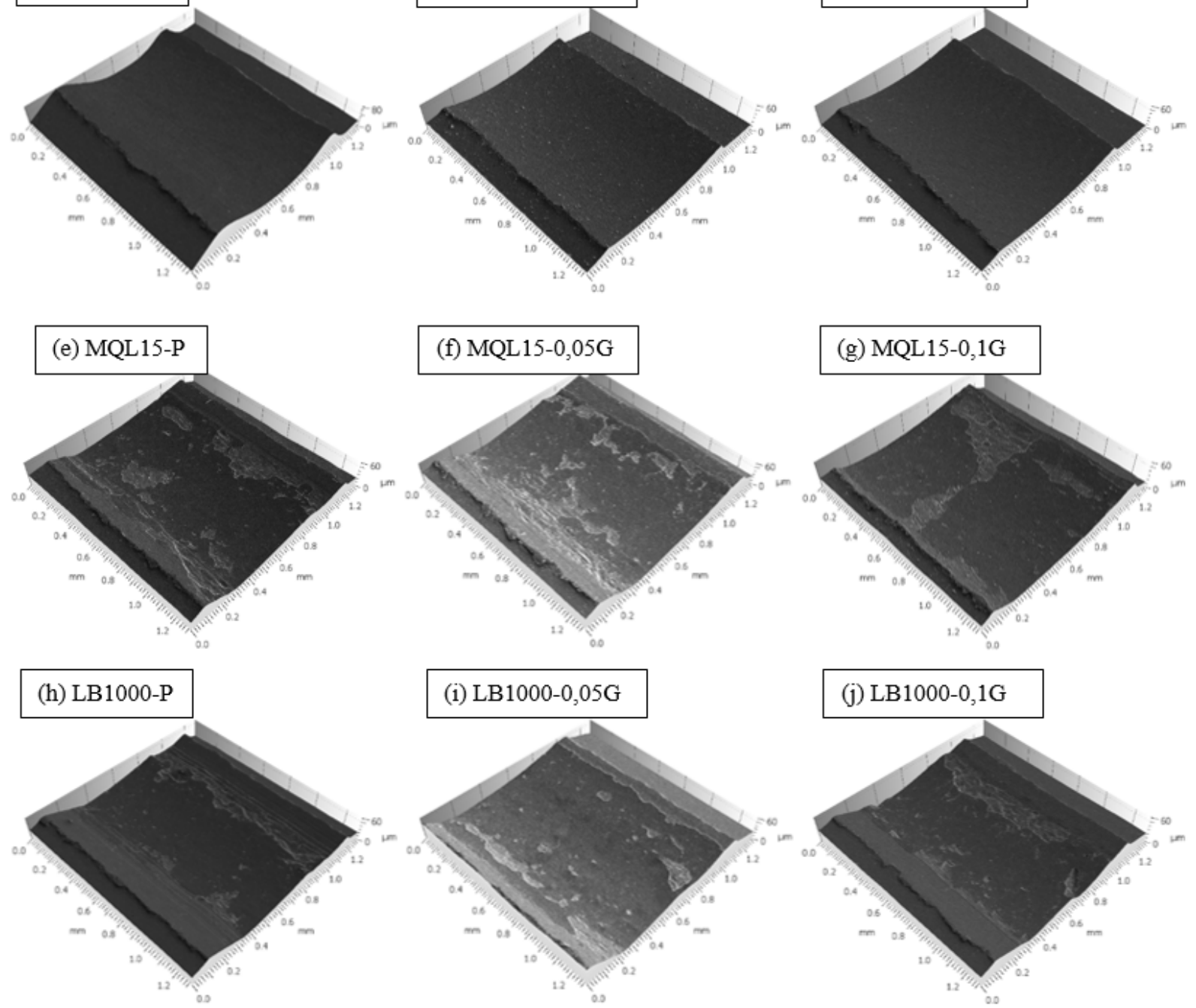

\section{Figure 11}

3D profiles of the wear tracks measured using the SEM images. 


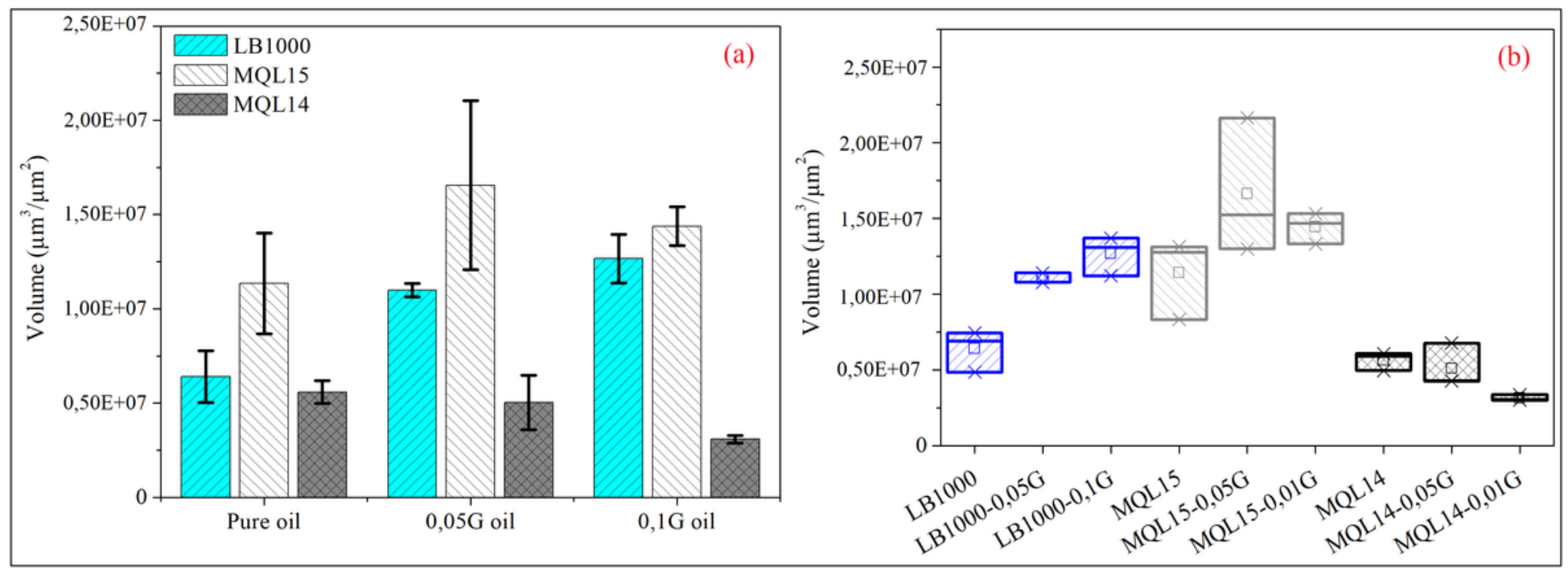

Figure 12

(a) Volume of material removed ( $\mu \mathrm{m} 3 / \mu \mathrm{m} 2)$; (b) Box plot.

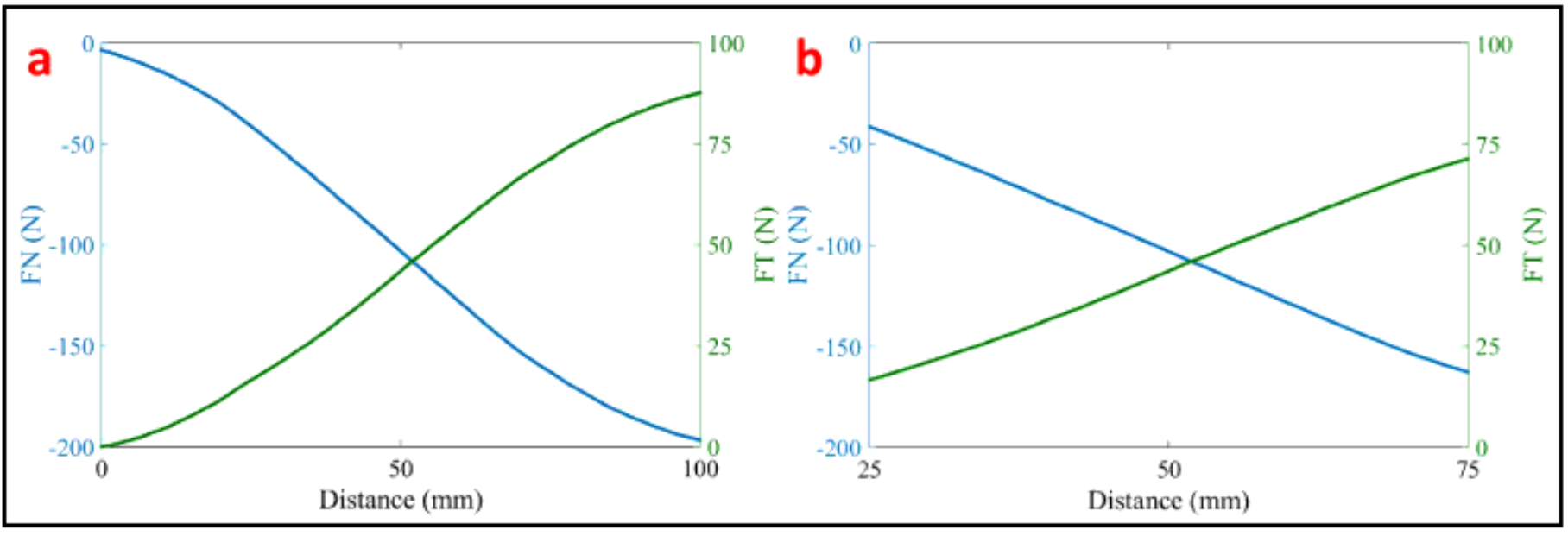

Figure 13

Identification of the region that obeys the Coulomb friction model in ramp milling [9]. (a) Tangential and normal forces during the whole ramp path. (b) The central region of the ramp was chosen for evaluation. 


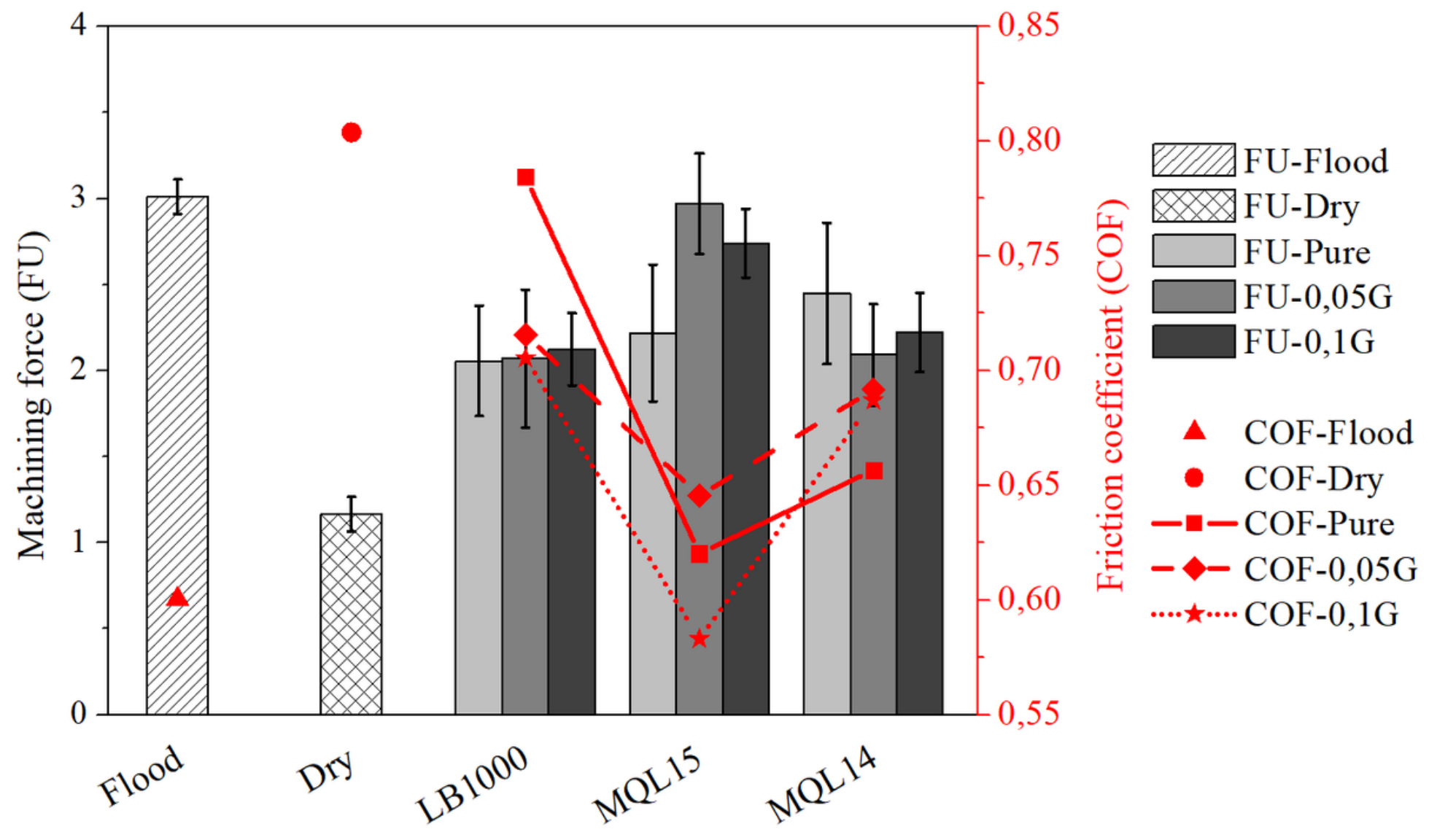

Figure 14

Results of the machining force and friction coefficient obtained in the ramp milling tests with several lubri-cooling conditions. 


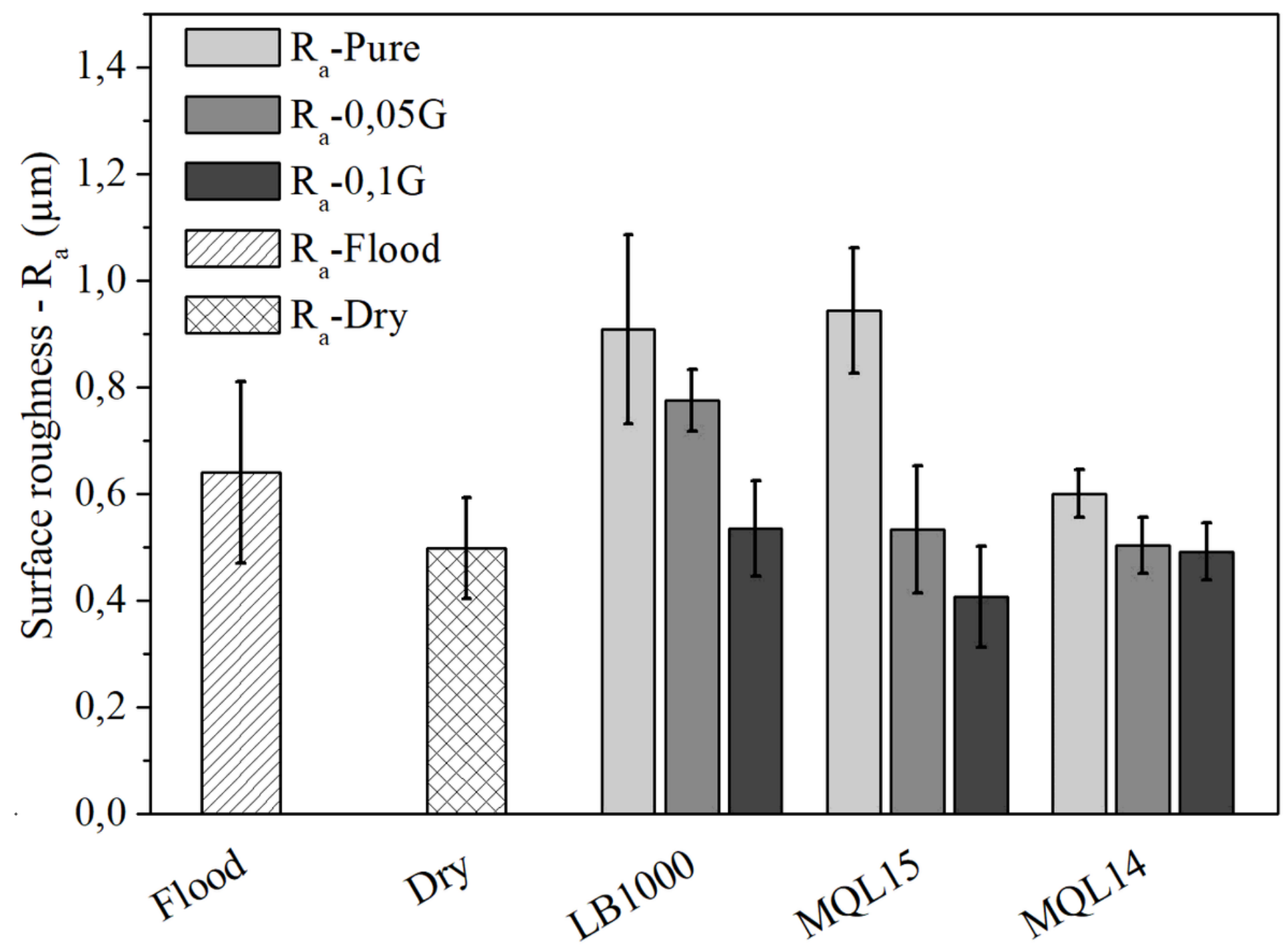

Figure 15

Illustration of Ra variations for dry and fluid test conditions. 